\title{
Experimental determination of melt interconnectivity and electrical conductivity in the upper mantle
}

\author{
Mickael LAUMONIER ${ }^{1 *}$, Robert FARLA ${ }^{1}$, Dan FROST ${ }^{1}$, Tomoo KATSURA ${ }^{1}$, Katharina \\ MARQUARDT $^{1}$, Anne-Sophie BOUVIER ${ }^{2}$, Lukas P. BAUMGARTNER ${ }^{2}$ \\ ${ }^{1}$ Bayerisches Geoinstitut, University of Bayreuth, Bayreuth, Germany \\ 2 Institute of Earth Science, University of Lausanne, Geopolis, 1015 Lausanne, Switzerland \\ *corresponding author: ML (mickael.laumonier@gmail.com)
}

\begin{abstract}
The presence of a small fraction of basaltic melt is a potential explanation for mantle electrical conductivity anomalies detected near the top of the oceanic asthenosphere. The interpretation of magnetotelluric profiles in terms of the nature and proportion of melt, however, relies on mathematical models that have not been experimentally tested at realistically low melt fractions $(<0.01)$. In order to address this, we have performed in situ electrical conductivity measurements on partially molten olivine aggregates. The obtained data suggest that the bulk conductivity follows the conventional Archie's law with the melt fraction exponent of 0.75 and 1.37 at melt fraction greater and smaller than 0.5 vol.\% respectively at $1350^{\circ} \mathrm{C}$. Our results imply multiple conducting phases in melt-bearing olivine aggregate and a connectedness threshold at $\sim 0.5 \mathrm{vol} . \%$ of melt. The model predicts that the conductive oceanic upper asthenosphere contain 0.5 to 1 vol.\% of melt, which is consistent with the durable presence of melt at depths over millions years while the oceanic plate spreads apart the mid-ocean ridge. A minimum permeability may allow the rise of Mid-Ocean Ridge Basalts where melt is likely to be present up to 4 vol.\% beneath the ridges.
\end{abstract}

Keywords (6 max)

Electrical conductivity; upper mantle; Low Velocity Zone; melt interconnectivity; olivine aggregate; basalt.

\section{Highlights}

- We measured the electrical conductivity (EC) of the melt-bearing olivine aggregate

- We note an melt interconnectivity threshold at a melt fraction of $0.5 \mathrm{vol} . \%$

- We model EC according to $\mathrm{T}^{\circ} \mathrm{C}$ and melt fraction using the conventional Archie's law

- The LVZ \& MORB production regions are explained by $<1$ and $<4 \%$ of melt respectively

- Low melt fraction $(<1 \%)$ is consistent with durable presence of melt at the LVZ

\section{One sentence summary}

We performed in situ electrical conductivity measurements on partially-molten olivine aggregate to check the mixing law models at low, realistic melt fraction potentially existing in the upper mantle. 


\section{Introduction}

One of the most striking geophysical anomalies identified in the upper mantle is the Low Velocity Zone (LVZ, e.g. Holtzman, 2016) characterized by low seismic velocities and high attenuation and located in the asthenosphere near the Lithosphere-Asthenosphere Boundary (LAB); under oceanic plates, the LVZ appears to coincide in some regions with a 20 to $50 \mathrm{~km}$ thick layer that possesses a high electrical conductivity (EC) (up to $\log \sigma=-0.3 ; \sigma$ in $\mathrm{S} / \mathrm{m}$ ) relative to overlying and underlying layers (e.g. Evans et al., 2005; Baba et al., 2006; Naif et al., 2013; Sarafian et al., 2015).

Several factors that might enhance EC have been invoked to explain these anomalies, such as anisotropy in mineral conductivity (e.g. Poe et al., 2010), water dissolved in nominally anhydrous minerals (e.g. Dai \& Karato, 2014), or the presence of melt (e.g. Gaillard et al., 2008; Yoshino et al., 2010a; Ni et al., 2010; Sifré et al., 2014). However, conductivity anisotropy in olivine aggregates appears to have an insufficient effect on EC to account for the observed mantle anomaly (Poe et al., 2010; Yang, 2012). In addition, water dissolved in olivine is unlikely to produce the conductivity anomalies observed in the upper mantle (Gardés et al., 2014) because the concentration of water in minerals required to reach upper mantle conductivities (100 to 1000 ppm; e.g. Dai \& Karato, 2014) would lead to partial melting of the mantle rocks, accompanied by partitioning of significant proportions of water into a melt phase rather than minerals (Hirschmann, 2006). Anisotropic distribution of the melt may also be a further factor enhancing the EC (Caricchi et al., 2011; Zhang et al., 2014; Pommier et al., 2015a). For these reasons, it seems that the presence of melt is the most likely explanation for the EC anomalies in the upper mantle, supported by melt-solid viscosity and density contrast (Sakamaki et al., 2013).

Large differences in transport properties between silicate minerals and melt mean that the EC of silicate melts is orders of magnitude higher than mineral phases (e.g. Tyburczy and Fisler, 1995). As a consequence, the bulk EC of partially molten rocks (minerals + melt) varies with the relative fraction of solid and liquid phases, but also with their respective distribution (Glover, 2010 and references therein). A liquid phase should form an interconnected network in a solid aggregate whenever dihedral angles between the two phases are lower than $60^{\circ}$. Since, in olivine aggregates, basaltic melt is distributed as pockets, tubes and films with dihedral angles as low as $\sim 10^{\circ}$, melt is expected to be interconnected and thus contributes to a significant increase of the EC even at melt fractions lower than 1\% (Cmíral et al., 1998; Yoshino et al., 2009; Faul \& Scott; 2006; Garapić et al., 2013).

The conductivity of a partially molten assemblage is generally calculated based on a mathematical model with an assumed mineral and melt geometry. The applicability of such models has, to date, not been experimentally investigated, particularly at very low ( $<1 \%)$ melt fractions, which are likely realistic for the upper mantle. Amongst the numerous mixing laws summarized and described by Glover (2010) and ten Grotenhuis et al. (2005), the conventional and modified Archie's laws appear very suitable for calculating the EC of upper mantle materials in which both solid and liquid phase contribute to the bulk conductivity according to defined exponents. Other models, such as the tubes, cubes, and sphere+ models (Grant \& West, 1965; Waff, 1974) texturally reproduce a melt-bearing aggregate with a melt fraction $>0.05$ where pockets (pools) and films wetting grain boundaries are the dominant features of the melt network (Miller et al., 2014). At melt fractions lower than 0.02, the melt principally forms channels residing along grain edges, and can still be interconnected down to very low melt fractions making those models misfit (Garapic et al., 2013; Holtzman, 2016). In spite of the proposed interconnectivity threshold (e.g. Holtzman, 2016), it is expected that the melt raises the bulk conductivity at these low $(<0.01 \%)$ melt fractions. 
Estimates for the amount of melt potentially present in the upper mantle is still quite uncertain due to a lack of experimental verification of models relating the degree of partial melt to the resulting EC, particularly at very low $(<1 \%)$ melt fractions. In order to find the most adequate mixing law for mantle rocks containing low melt fractions, we have performed in situ electrical conductivity measurements on olivine aggregate with melt fraction varying from 0 to 100 vol.\% at pressures and temperatures up to $3 \mathrm{GPa}$ and $1430^{\circ} \mathrm{C}$ respectively. From the results, we build a model based on the conventional Archie's law, which is valid over large range of temperature and melt fraction. Then, we discuss the amount of melt potentially existing in the upper mantle, and its mobility. In addition, we estimate the temperature distribution in the asthenosphere without melt based on the present conductivity measurements of melt-free olivine aggregates.

\section{Experimental procedure}

\subsection{Starting materials and sample preparation}

Natural olivine from a Lanzarote peridotite (Canary Islands, Spain) and synthetic basalt were employed as solid and liquid starting materials respectively. The Lanzarote olivine consists of a single chemically homogeneous population of Fo92 (Table 1). Optical impurity-free olivine grains were crushed and sieved to obtain a maximum grain size of 100 micrometers. Olivine was used without further treatment (e.g. annealing under special conditions) so as to remain close to natural mantle materials. The basaltic glass was produced by mixing reagent grade oxides and carbonates and fusing the mixture twice in an iron-enriched platinum crucible at $1450^{\circ} \mathrm{C}$ and 1 atmosphere for 3 hours. The resulting homogeneous glass had a composition similar to that of a Mid-Ocean Ridge Basalt (termed "synthesis", Table 1). Gadolinium was added to the melt (a very incompatible element that concentrates exclusively in the liquid) for neutron tomography observations that are not reported here. The same batch of basalt was used for all experiments. Its liquidus temperature was estimated to be approximately $1270^{\circ} \mathrm{C}$ at $1.5 \mathrm{GPa}$ from the melting temperature during synthesis and from EC measurements with the sample with $100 \%$ of melt. The glass was then cored to provide starting samples of basalt i.e. for $100 \%$ melt fraction experiments, while the rest of the glass was crushed into a fine powder $(\sim 5$ micrometers grain size). This powder was mechanically mixed with olivine grains in order to distribute the glass as homogeneously as possible within the olivine aggregate. Each component was accurately weighed (precision of 0.1 micrograms) to achieve the desired melt fraction, assuming very little density variation between room and experimental conditions (Sakamaki et al., 2013). The mixtures are named according to the volume fraction of added basaltic glass (see also section 4.1). The mixtures and the olivineonly aggregate were cold-pressed using a hydraulic press and jig to provide samples $3 \mathrm{~mm}$ in diameter and 1.0 to $1.4 \mathrm{~mm}$ in length.

\subsection{In situ electrical conductivity measurements}

In every experiment, the sample was placed between two platinum foils (electrodes) in contact with two thermocouples forming the electrical cell (Fig. 1). An MgO sleeve chemically and electrically insulates the sample from the graphite furnace (see Fig. SI1). Crushable and hard alumina pistons were placed either side of the sample, which was positioned within the hot zone at the centre of the assembly. This zone extending over $\sim 1.5 \mathrm{~mm}$, and was determined by two thermocouples that measured the temperature $\sim 0.3 \mathrm{~mm}$ away from each edge of the sample. Experiments where a temperature difference larger than $20^{\circ} \mathrm{C}$ between the 2 thermocouples was measured, were discarded to avoid EC uncertainties due to large temperature gradients. The furnace and inner parts of the assembly were inserted in a zirconia cylinder used as thermal insulator that was inserted in an unfired 12-mm edge length pyrophyllite cube. Because of the graphite furnace, the absence of a welded-shut capsule and the presence of olivine, oxygen fugacity is believed to approximate FMQ ( \pm 1.5 Log unit) 
conditions Confining pressure was applied to the cube by a six-ram press (MAVO press, Bayerisches Geoinstitute) employing second stage anvils with square truncations of 9-mm

\begin{tabular}{|c|c|c|c|c|c|c|c|c|c|c|c|c|c|}
\hline \#Exp & $\mathrm{SiO}_{2}$ & $\mathrm{TiO}_{2}$ & $\mathrm{Al}_{2} \mathrm{O}_{3}$ & $\mathrm{Cr}_{2} \mathrm{O}_{3}$ & $\mathbf{G d}_{2} \mathbf{O}_{3}$ & FeO & MgO & $\mathrm{NiO}$ & MnO & $\mathrm{CaO}$ & $\mathrm{Na}_{2} \mathrm{O}$ & $\mathrm{K}_{2} \mathrm{O}$ & Total* \\
\hline Olivine (54) & $\begin{array}{r}39.78 \\
0.75\end{array}$ & $\begin{array}{l}0.01 \\
0.01\end{array}$ & $\begin{array}{l}0.02 \\
0.02\end{array}$ & $\begin{array}{l}0.04 \\
0.07\end{array}$ & & $\begin{array}{l}8.21 \\
0.20\end{array}$ & $\begin{array}{r}51.37 \\
0.64\end{array}$ & $\begin{array}{l}0.38 \\
0.05\end{array}$ & $\begin{array}{l}0.12 \\
0.04\end{array}$ & $\begin{array}{l}0.06 \\
0.02\end{array}$ & $\begin{array}{l}0.01 \\
0.01\end{array}$ & & \\
\hline nominal & 52 & & 15 & & 2 & 7.5 & 8.5 & & & 10 & 3 & 2 & 100 \\
\hline Synthesis (20) & $\begin{array}{r}52.00 \\
0.31\end{array}$ & $\begin{array}{l}0.01 \\
0.01\end{array}$ & $\begin{array}{r}15.34 \\
0.19\end{array}$ & & $\begin{array}{l}1.88 \\
0.23\end{array}$ & $\begin{array}{l}6.81 \\
0.17\end{array}$ & $\begin{array}{r}8.68 \\
0.17\end{array}$ & & $\begin{array}{l}0.02 \\
0.02\end{array}$ & $\begin{array}{r}10.20 \\
0.13\end{array}$ & $\begin{array}{r}3.10 \\
0.10\end{array}$ & $\begin{array}{l}1.96 \\
0.04\end{array}$ & $\begin{array}{r}98.71 \\
2.71\end{array}$ \\
\hline $\begin{array}{l}\text { M480 - 100\% } \\
(16)\end{array}$ & $\begin{array}{r}48.27 \\
0.40\end{array}$ & $\begin{array}{l}0.01 \\
0.02\end{array}$ & $\begin{array}{r}14.38 \\
0.35\end{array}$ & & $\begin{array}{l}1.80 \\
0.14\end{array}$ & $\begin{array}{r}6.15 \\
0.17\end{array}$ & $\begin{array}{r}13.58 \\
0.96\end{array}$ & & $\begin{array}{r}0.01 \\
0.01\end{array}$ & $\begin{array}{r}10.43 \\
0.32\end{array}$ & $\begin{array}{r}3.28 \\
0.16\end{array}$ & $\begin{array}{r}2.09 \\
0.13\end{array}$ & $\begin{array}{r}97.75 \\
0.53\end{array}$ \\
\hline $\begin{array}{l}\text { M484 - 10\% } \\
(15)\end{array}$ & $\begin{array}{r}48.86 \\
0.73\end{array}$ & $\begin{array}{r}0.03 \\
0.02\end{array}$ & $\begin{array}{r}12.19 \\
0.82\end{array}$ & & $\begin{array}{l}1.64 \\
0.24\end{array}$ & $\begin{array}{l}9.59 \\
0.56\end{array}$ & $\begin{array}{r}11.34 \\
1.62\end{array}$ & & $\begin{array}{l}0.15 \\
0.05\end{array}$ & $\begin{array}{r}10.98 \\
0.55\end{array}$ & $\begin{array}{r}3.02 \\
0.22\end{array}$ & $\begin{array}{r}2.19 \\
0.23\end{array}$ & $\begin{array}{r}97.98 \\
0.48\end{array}$ \\
\hline $\begin{array}{l}\text { M477 - 4\% } \\
(11)\end{array}$ & $\begin{array}{r}50.21 \\
1.10\end{array}$ & $\begin{array}{r}0.04 \\
0.02\end{array}$ & $\begin{array}{r}15.28 \\
2.62\end{array}$ & & $\begin{array}{r}2.18 \\
0.16\end{array}$ & $\begin{array}{l}7.31 \\
0.86\end{array}$ & $\begin{array}{r}8.77 \\
0.93\end{array}$ & & $\begin{array}{r}0.19 \\
0.03\end{array}$ & $\begin{array}{r}10.67 \\
0.39\end{array}$ & $\begin{array}{l}3.17 \\
0.06\end{array}$ & $\begin{array}{r}2.19 \\
0.10\end{array}$ & $\begin{array}{r}96.69 \\
0.63\end{array}$ \\
\hline $\begin{array}{l}\text { M486 - 2\% } \\
(14)\end{array}$ & $\begin{array}{r}49.75 \\
0.52\end{array}$ & $\begin{array}{l}0.07 \\
0.02\end{array}$ & $\begin{array}{r}11.65 \\
0.79\end{array}$ & & $\begin{array}{l}1.40 \\
0.17\end{array}$ & $\begin{array}{l}9.76 \\
0.50\end{array}$ & $\begin{array}{r}11.14 \\
0.83\end{array}$ & & $\begin{array}{l}0.19 \\
0.04\end{array}$ & $\begin{array}{r}10.82 \\
0.65\end{array}$ & $\begin{array}{r}3.18 \\
0.36\end{array}$ & $\begin{array}{l}2.06 \\
0.27\end{array}$ & $\begin{array}{r}98.48 \\
0.52\end{array}$ \\
\hline M487 - 1\% (8) & $\begin{array}{r}48.65 \\
2.40\end{array}$ & $\begin{array}{r}0.11 \\
0.05\end{array}$ & $\begin{array}{r}11.43 \\
0.76\end{array}$ & & $\begin{array}{l}1.18 \\
0.25\end{array}$ & $\begin{array}{l}9.50 \\
0.64\end{array}$ & $\begin{array}{r}13.45 \\
1.23\end{array}$ & & $\begin{array}{l}0.15 \\
0.06\end{array}$ & $\begin{array}{r}10.79 \\
2.59\end{array}$ & $\begin{array}{l}3.00 \\
0.43\end{array}$ & $\begin{array}{l}1.73 \\
0.32\end{array}$ & $\begin{array}{r}95.90 \\
1.10\end{array}$ \\
\hline $\begin{array}{l}\text { M488 - 0.5\% } \\
\text { (29) }\end{array}$ & $\begin{array}{r}49.90 \\
0.62\end{array}$ & $\begin{array}{l}0.01 \\
0.01\end{array}$ & $\begin{array}{r}14.15 \\
0.33\end{array}$ & & $\begin{array}{l}1.76 \\
0.24\end{array}$ & $\begin{array}{l}8.45 \\
0.38\end{array}$ & $\begin{array}{r}8.81 \\
0.69\end{array}$ & & $\begin{array}{r}0.08 \\
0.03\end{array}$ & $\begin{array}{r}12.48 \\
0.67\end{array}$ & $\begin{array}{l}2.67 \\
0.17\end{array}$ & $\begin{array}{l}1.69 \\
0.14\end{array}$ & $\begin{array}{r}97.21 \\
0.91\end{array}$ \\
\hline $\begin{array}{l}\text { M501-0.5\% } \\
\text { (4) }\end{array}$ & $\begin{array}{r}52.09 \\
1.10\end{array}$ & $\begin{array}{r}0.05 \\
0.02\end{array}$ & $\begin{array}{r}13.54 \\
0.67\end{array}$ & & $\begin{array}{l}1.25 \\
0.14\end{array}$ & $\begin{array}{l}9.57 \\
0.28\end{array}$ & $\begin{array}{r}10.93 \\
2.50\end{array}$ & & $\begin{array}{r}0.00 \\
0.00\end{array}$ & $\begin{array}{l}8.77 \\
1.35\end{array}$ & $\begin{array}{l}2.47 \\
0.19\end{array}$ & $\begin{array}{l}1.34 \\
0.12\end{array}$ & $\begin{array}{r}98.45 \\
0.59\end{array}$ \\
\hline $\begin{array}{l}\text { M510 - } 0.25 \% \\
\text { (11) }\end{array}$ & $\begin{array}{r}51.45 \\
1.13\end{array}$ & $\begin{array}{l}0.05 \\
0.03\end{array}$ & $\begin{array}{r}10.78 \\
0.70\end{array}$ & & $\begin{array}{l}1.14 \\
0.24\end{array}$ & $\begin{array}{l}7.83 \\
1.16\end{array}$ & $\begin{array}{r}15.20 \\
2.22\end{array}$ & & $\begin{array}{l}0.15 \\
0.04\end{array}$ & $\begin{array}{l}9.31 \\
0.69\end{array}$ & $\begin{array}{l}2.97 \\
0.37\end{array}$ & $\begin{array}{l}1.10 \\
0.07\end{array}$ & $\begin{array}{r}97.42 \\
0.49\end{array}$ \\
\hline
\end{tabular}

Table 1: Chemical compositions and standard deviations (italic grey font) of the starting materials (Olivine \& Synthesis, whereby the nominal and the analyzed composition of the latter are reported) and melt compositions after experiments. All analyses were normalized to $100 \mathrm{wt}$.\%, and the total (*) shows the sum of oxides before correction. The number of analyses performed is indicated after the name of each experiment.

In situ EC measurements were performed using a Solartron impedance gain phase analyzer connected to the 4 wires of the 2 thermocouples (see details about impedance spectroscopy in Barsoukov \& Macdonalds, 2005, for instance). The very low resistance of the liquid basalt required the use of the 4-wire method for accurate EC measurements, as the internal resistance of a 2-wire measurement is significant (see Fig. SI 2). The graphite furnace was heated manually by controlling the electrical power and acted as a grounded Faraday cage, causing only a minor amount of inductive interference in the frequency range 50 to $250 \mathrm{~Hz}$. In a typical run the sample was pressurized for one hour, followed by a heating and cooling cycle, during which impedance spectra were acquired. The 2 thermocouples were switched between the temperature monitor and the impedance spectrometer to avoid interference. After each increase or decrease in temperature the sample was allowed to reach a stable temperature over a period $\sim 1$ minute before the sample resistance was measured. Impedance spectra were typically acquired in a frequency range from $1 \mathrm{MHz}$ to $10 \mathrm{~Hz}$ depending on the signal response of the sample and the temperature (Fig. 2). The temperature was monitored before and after the resistance measurement and was generally found to have remained constant. The measurement was repeated when the temperature was found to have deviated by more than $5^{\circ} \mathrm{C}$ during the resistance acquisition. Uncertainties on the sample conductivity arise from the sample geometry, temperature measurement and deviation during the measurement and from the determination of the resistance. The total uncertainty calculated 
by propagating these errors is 0.2 Log units (Laumonier et al., 2015). At the end of the experiment, the furnace power was switched off to quench the sample before slow decompression.

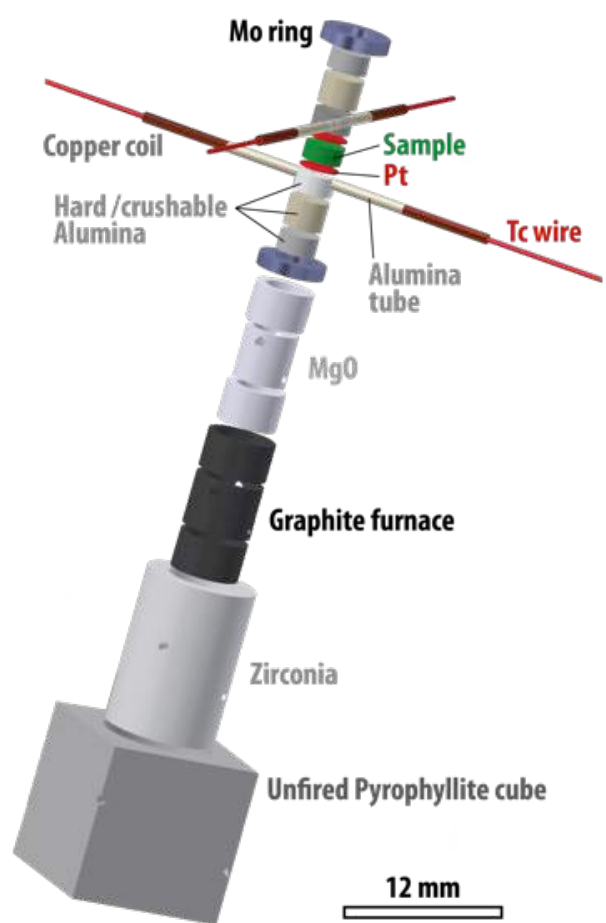

Figure 1: The 12-millimeter assembly employed for in situ electrical conductivity measurements with the MAVO 6ram press. The sample (green) diameter is 3 millimeters before compression. The electrical path (red) includes platinum foil electrodes which sandwich the sample and are in contact with 2 S-type thermocouples connected interchangeably to a temperature monitor and a gain phase impedance analyzer.
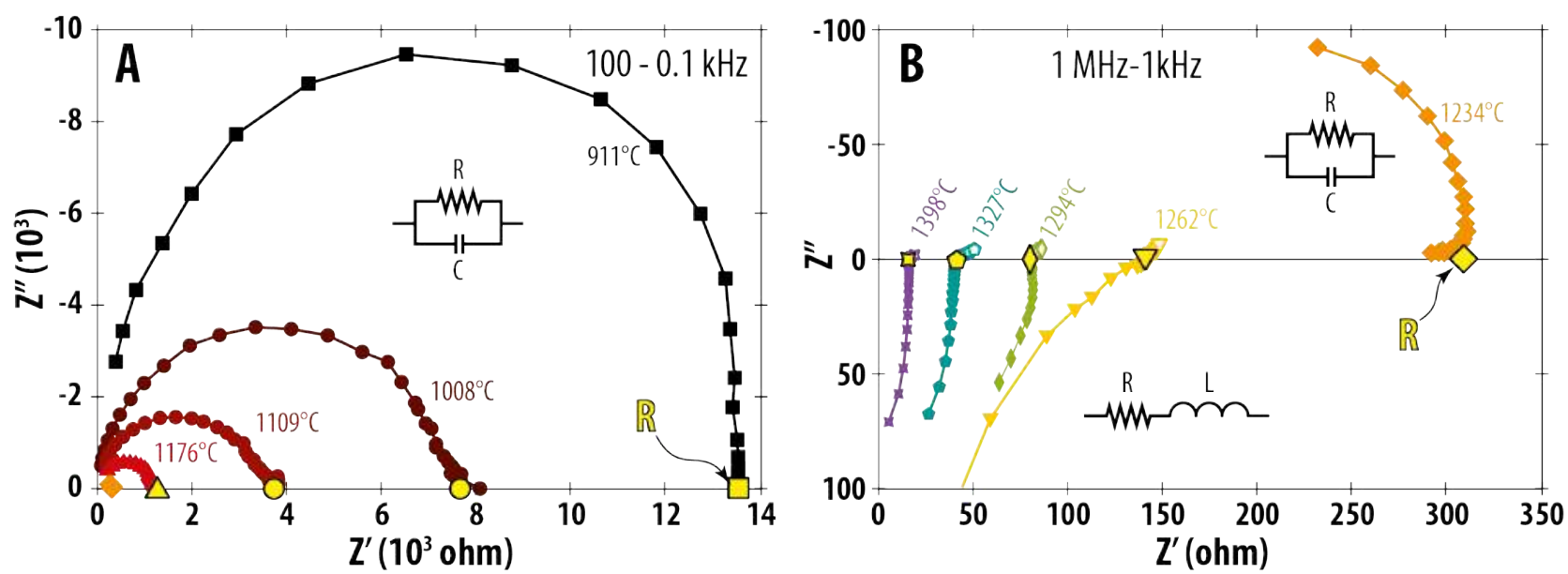

Figure 2: Impedance spectra in the Nyquist plane and equivalent electrical circuits (Huebner \& Dillenburg, 1995) obtained at low $\left(\mathrm{A}: \mathrm{T}<1200^{\circ} \mathrm{C}\right)$ and high $\left(\mathrm{B}: \mathrm{T}>1200^{\circ} \mathrm{C}\right)$ temperatures on the pure basalt sample. $R, C$ and $L$ in electrical circuits stand for resistance, capacitance and inductance respectively. The real resistance (yellow $R$ ) is shown by a yellow symbol.

Electrical conductivity mechanisms for minerals and melts have been extensively described in the literature (e.g. Roberts \& Tyburczy, 1999; Gaillard, 2004; Yoshino et al., 2010b; Yoshino \& Katsura, 2013; Laumonier et al., 2015). It is worth to recall, however, the temperature dependence of the electrical conductivity $\sigma(\mathrm{S} / \mathrm{m})$ according to the Arrhenius Law:

$$
\sigma=\sigma_{0} \exp ^{-\left(E_{a}+P \Delta V / \Re T\right)}
$$


where $\sigma_{0}, E_{a}, P, \Delta V$ and $\Re$ are a pre-exponential term $(\mathrm{S} / \mathrm{m})$, the activation energy $(\mathrm{J} / \mathrm{mol})$, the

\subsection{Post-experiment analysis}

Once recovered, the assembly was cut in the middle along an axial plane of the sample, mounted in epoxy resin and polished for textural and chemical analyses. The distribution of the melt and the sample dimensions were characterized by Scanning Electron Microscopy (SEM) with a typical acceleration voltage of 20 to $22 \mathrm{kV}$. Crystal size distribution and orientation were measured by Electron Backscatter Diffraction on a ZEISS SEM, Leo Gemini 1530 with a Schottky field emission gun employing an accelerating voltage of $20 \mathrm{keV}$ and a beam current of about 2.0 -2.5 nA using a $60 \mathrm{~mm}$ aperture (more details about the methods in Supplementary Information).

Chemical compositions of melt and minerals (olivine) were quantified by an Electron Probe Micro Analyzer with unfocused (10 micrometers) and focused (1 micron) beams respectively, with an acceleration voltage of $15 \mathrm{kV}$ and beam current of $150 \mathrm{nA}$. The water content was measured using the Cameca IMS $1280 \mathrm{HR}$ at the Swiss SIMS laboratory of the University of Lausanne (Switzerland) under a $10 \mathrm{kV} \mathrm{Cs}^{+}$primary beam with a $\sim 1.5 \mathrm{nA}$ current, resulting in a typical spot size of $\sim 10 \mu \mathrm{m}$. To minimize the water background in the machine, samples were mounted in indium with a reference material. Before each measurement, the surface was cleaned using a $25 \mu$ rastered presputtering beam, for 240 seconds (more details about the methods in Supplementary Information).

\section{Results}

Table 2 shows the experimental conditions and fitting parameters for the eleven experiments conducted with in situ EC measurements. One run was performed at a constant temperature (M523) while all others followed similar heating and cooling cycles. All experiments were carried out at a pressure of $1.5 \mathrm{GPa}$, except M501 that was conducted at $3 \mathrm{GPa}$ in order to investigate the effect of pressure on EC. The explored melt fraction, based on the initial fraction of added basaltic glass, ranges from 0 (olivine-only) to $100 \mathrm{vol} \%$ (basaltic melt only).

\begin{tabular}{|c|c|c|c|c|c|c|c|c|c|c|}
\hline $\operatorname{Exp} \#$ & $\begin{array}{c}\text { Pressure } \\
\text { (GPa) }\end{array}$ & $\begin{array}{c}\text { Duration } \\
\text { (min) }\end{array}$ & $\begin{array}{c}\text { added } \\
\text { basalt } \\
\text { (vol.\%) }\end{array}$ & $\begin{array}{l}\text { Geometrical } \\
\text { factor }\left(10^{-3}\right)\end{array}$ & $\begin{array}{c}\mathrm{T}\left({ }^{\circ} \mathrm{C}\right) \\
\text { before } \\
\text { quench }\end{array}$ & $\begin{array}{c}\text { Duration } \\
\text { before } \\
\text { quench } \\
\text { (min) } \\
\end{array}$ & $\begin{array}{l}\mathrm{T}\left({ }^{\circ} \mathrm{C}\right) \\
\max \end{array}$ & $\begin{array}{l}\mathrm{T}\left({ }^{\circ} \mathrm{C}\right) \\
\mathrm{min}\end{array}$ & $E_{a}(k J)$ & $\log \sigma_{0}$ \\
\hline M496 & 1.5 & 331 & 0.0 & 5.90 & 1348 & 16 & 1348 & 1192 & $239(11)$ & $5.84(0.39)$ \\
\hline M502 & 1.5 & 203 & 0.15 & 4.16 & 1307 & 23 & 1289 & 1164 & $163(3)$ & $3.66(0.10)$ \\
\hline M510 & 1.5 & 131 & 0.25 & 4.83 & 1354 & 21 & 1360 & 1182 & $177(3)$ & $4.41(0.09)$ \\
\hline M488 & 1.5 & 399 & 0.5 & 2.78 & 1373 & 35 & 1373 & 1205 & $162(5)$ & $4.54(0.16)$ \\
\hline M487 & 1.5 & 238 & 1.0 & 2.76 & 1346 & 102 & 1430 & 1292 & $195(4)$ & $5.70(0.14)$ \\
\hline M486 & 1.5 & 181 & 2.0 & 3.24 & 1373 & 15 & 1391 & 1266 & $191(8)$ & $5.80(0.28)$ \\
\hline M478 & 1.5 & 308 & 4.0 & 1.69 & 1395 & 25 & 1418 & 1214 & $207(4)$ & $6.52(0.14)$ \\
\hline
\end{tabular}

Table 2: Experimental conditions for EC measurements and fitted activation energy $E_{a}$ and preexponential factor $\sigma_{0}(\mathrm{~S} / \mathrm{m})$, with standard deviations into brackets. $\mathrm{T}^{\circ} \mathrm{C}$ max to $\mathrm{T}^{\circ} \mathrm{C}$ min defines the temperature interval for the fitting of $E_{a}$ and $\sigma_{0}$.

\subsection{Electrical conductivity of melt-bearing olivine aggregates}

The EC of the olivine-only sample (M496) for several heating-cooling cycles is shown in Figure 3. During the first heating, the EC increased with temperature, corresponding to a low activation energy $\left(\mathrm{E}_{\mathrm{a}} \sim 50 \mathrm{~kJ} / \mathrm{mol}\right)$, likely due to the presence of moisture up to $\sim 700^{\circ} \mathrm{C}$. Between $\sim 800$ and $\sim 1230^{\circ} \mathrm{C}, \mathrm{E}_{\mathrm{a}}$ is a factor of two higher than at lower temperatures $\left(\mathrm{E}_{\mathrm{a}} \sim 100\right.$ 
$\mathrm{kJ} / \mathrm{mol}$ ) due to hopping (also called small polaron) conduction and potential grain boundary effects (Wannamaker \& Duba, 1993; Sakamoto et al., 2002; Yoshino et al., 2009). At temperatures above $1230^{\circ} \mathrm{C}$, high $\mathrm{E}_{\mathrm{a}}(239 \pm 11 \mathrm{~kJ} / \mathrm{mol})$ indicates that ionic conduction (e.g. Yoshino et al., 2009) is the dominant mechanism, although there may still be minor contributions from other mechanisms (see also Gardés et al., 2014).

The conductivity of sample M510 that contained 0.25 vol. $\%$ of added basalt is similar to that of pure olivine below the basalt liquidus temperature $\left(1270^{\circ} \mathrm{C}\right)$, but it becomes significantly higher than olivine at temperatures above $1300^{\circ} \mathrm{C}$ (Fig. 3). However, during the following cooling and heating cycles, the conductivity remains higher than that for pure olivine, probably due to the better wetting properties of melt once it has overshot the liquidus temperature and distributed through the solid matrix. The effect of crossing the solidus temperature of the basalt is not visible in the experiment involving $0.25 \mathrm{vol} . \%$ of added basalt, probably due to the low amount and initial distribution of melt (Fig. 3).

In the case of the sample composed of basaltic melt only (M480), the jump observed around $880^{\circ} \mathrm{C}$ during the first heating can be explained by improved contact between sample and electrodes upon relaxation of the glass once the glass transition temperature has been crossed. Around $1090^{\circ} \mathrm{C}$ (grey arrow on Fig. 3), the slope suddenly increases from $74 \pm 9$ to $248 \pm 10 \mathrm{~kJ}$, probably coinciding with the solidus temperature of the basalt. The value of 248 $\mathrm{kJ}$ has no physical meaning because the basaltic glass may have partly crystallized, and the formed crystals may have gradually melted at these temperatures. The very good reproducibility of the conductivity measurements during the different heating and cooling cycles attests to the accuracy of the measurements and the limited loss of melt from the sample chamber (see also section 4.1).

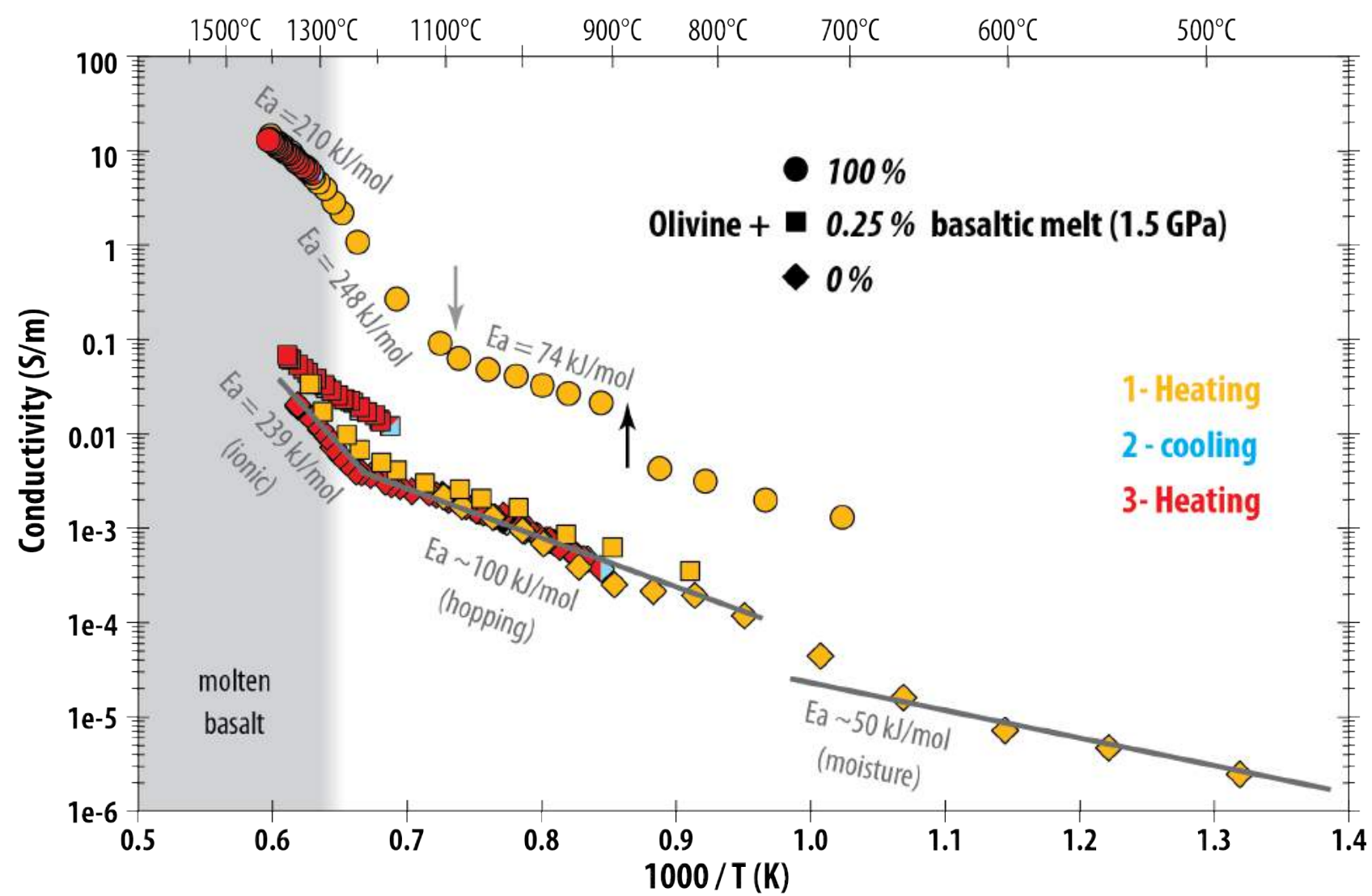

Figure 3: Reciprocal temperature versus electrical conductivity of samples containing $0,0.25$ and $100 \%$ of basaltic melt at $1.5 \mathrm{GPa}$. The activation energy (Ea) is indicated for the pure olivine sample, with probable conduction mechanisms. Black and grey arrows correspond to feature most likely caused by the glass transition and the solidus of the basalt respectively. The conductivity values obtained during cooling are superimposed by the last heating path. The error in temperature is smaller than the symbols while the maximum error in EC is $0.2 \log$ unit. 
The logarithmic EC of the pure olivine aggregate and of olivine aggregates containing various fractions of basaltic melt are displayed as a function of reciprocal temperature in Fig. 4. For all melt fractions investigated, the EC increases with the temperature but is clearly very sensitive to the fraction of melt: the higher the melt fraction, the higher the conductivity. For instance, at $1300^{\circ} \mathrm{C}$, the addition of 0.5 vol. $\%$ of basaltic melt increases the EC by one order of magnitude compared to the pure olivine aggregate; the addition of $10 \mathrm{vol} \%$ of melt increases the EC by 1.8 log unit, and the pure basalt liquid end-member is by 2.6 orders of magnitude more conductive. These relations are not affected by run duration: experiment M523 was performed at a single temperature of $1319^{\circ} \mathrm{C}$ for 27 hours, but the conductivity is consistent with data from M510 which contained the same melt fraction but followed a temperaturetime cycle similar to the other experiments (Fig. 4; see also Fig SI 3). M488 and M501 both contained a basalt melt fraction of 0.5 vol.\% and were conducted at 1.5 and $3.0 \mathrm{GPa}$ respectively have identical conductivities within the error.

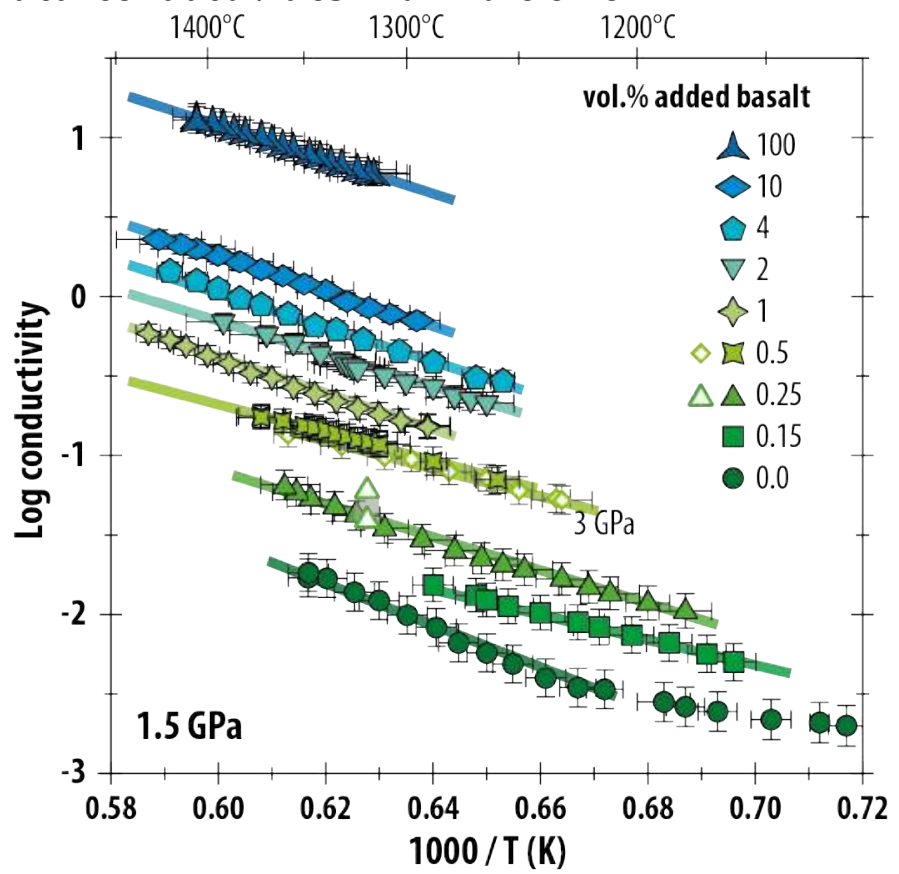

Figure 4: Reciprocal temperature versus EC of basaltic melt and olivine aggregate with 0 to 10 vol.\% of added basaltic melt at $1.5 \mathrm{GPa}$ (symbols). An olivine aggregate experiment containing $0.5 \mathrm{vol} . \%$ of added basalt was also conducted at $3 \mathrm{GPa}$ (empty diamonds). The range of conductivity measured at constant temperature in experiment M523 is shown by the empty triangles. Lines correspond to the fit of the data using equation (1) and fitting parameters are presented in Table 2.

\subsection{Textural results}

SEM observations of the recovered experimental charges showed that the initial cylindrical shape of the sample was preserved through the experiment with only minor irregularities, mainly where the electrodes are in contact with the thermocouples (Fig. 5; Fig. SI 4). The horizontal cracks observed throughout the sample may have been caused by tensile stresses during decompression and were omitted from the calculation of the geometrical factor (corresponding to aspect ratio of the sample, i.e. the surface divided by the length; Table 2). The grain size ranges up to 100 microns, but shows no significant grain growth over the duration of the experiments (Fig. SI 5). The effect of grain size on EC was not investigated here. Low magnification images show a relatively homogeneous distribution of melt, which is visible as pockets $\sim 50$ microns across in the experiment where $\leq 2 \mathrm{vol} . \%$ of melt was added (Fig. 5A, C \& F). The elongated melt pockets appear to follow the flow lines typically induced by compressive deformation, i.e. sub-normal to the electrodes at the top and bottom of the sample, rotating sub-parallel to the electrodes in the centre of the sample, suggesting a small 
deviatoric stress was present during the experiments (Fig. 5A and Fig. SI 4C; see more in Section 4.1). At higher magnification, we note the presence of melt as films and tubes, displayed as lines and dots respectively in 2D sections (examples of the labels on Fig. 5B). The melt appears to be fully interconnected for basalt melt fractions $\geq 2$ vol.\% but not interconnected at fractions $<0.5 \%$ (Fig. $5 \mathrm{D} \& \mathrm{G}$ ). A comparison in the distribution of calcium between experiments with 0.5 and 0.25 vol.\% melt contents reveals the presence of small melt-associated Ca-rich pockets in both samples but Ca-rich films are not visible in the sample with 0.25 vol.\% of added melt (Fig. 5 E \& H).

\subsection{Chemical composition and water content of experimental products}

The chemical composition of olivine after experiments is almost identical to the starting composition (Fig. SI 6). The slight increase of the Fo content, by up to $\sim 0.01$ (molar $\mathrm{Mg} / \mathrm{Fe}+$ $\mathrm{Mg}$ ) ), is probably related to minor reaction with the MgO capsule (see section 1 of supplementary materials), slight loss of Fe to the Pt electrodes and/or a minor readjustment in mineral/melt Fe-Mg partitioning.

The chemical composition of the melt in the experimental products is similar to that of the starting basaltic melt (Table 1). There is some variation apparent in the concentrations of $\mathrm{MgO}, \mathrm{Al}_{2} \mathrm{O}_{3}$, and $\mathrm{FeO}$ and a small variation in the sodium concentration (electrical charge carriers) but none of these differences exceed 10\%, except for the experiments with a basalt fraction of 0.5 vol.\% that show changes that are slightly larger than this. The chemical compositions and textural observations give no indication that interactions occurred between olivine crystals and melt that could have significantly affected the EC measurements.

The water content measured in olivine is below the detection threshold, thus implying a concentration of water lower than $10 \mathrm{ppm}$ in the solid material, in comparison with the dry forsterite used as a calibration standard. In contrast, the glasses contain substantial amounts of water, with the experiments containing the lower melt fractions producing the most hydrous glasses (Fig. 6). The experiment with no crystals produced a glass with little water ( 0.1 wt. $\% \mathrm{H}_{2} \mathrm{O}$ ), slightly more than the starting glass (0.03 wt.\%). Experiments with lower melt fractions resulted in glasses containing between 0.54 wt. $\% \mathrm{H}_{2} \mathrm{O}(10 \mathrm{vol} . \%$ of added basalt) and $0.74 \mathrm{wt} . \% \mathrm{H}_{2} \mathrm{O}$ (2 vol.\% of added basalt) (Fig. 6$)$. The glasses from the experiments with $0.25,0.5$ and 2 vol.\% added melt have similar water contents but there is no clear a correlation between the water content in the experimental glasses and the added melt fraction (Fig. 6). 

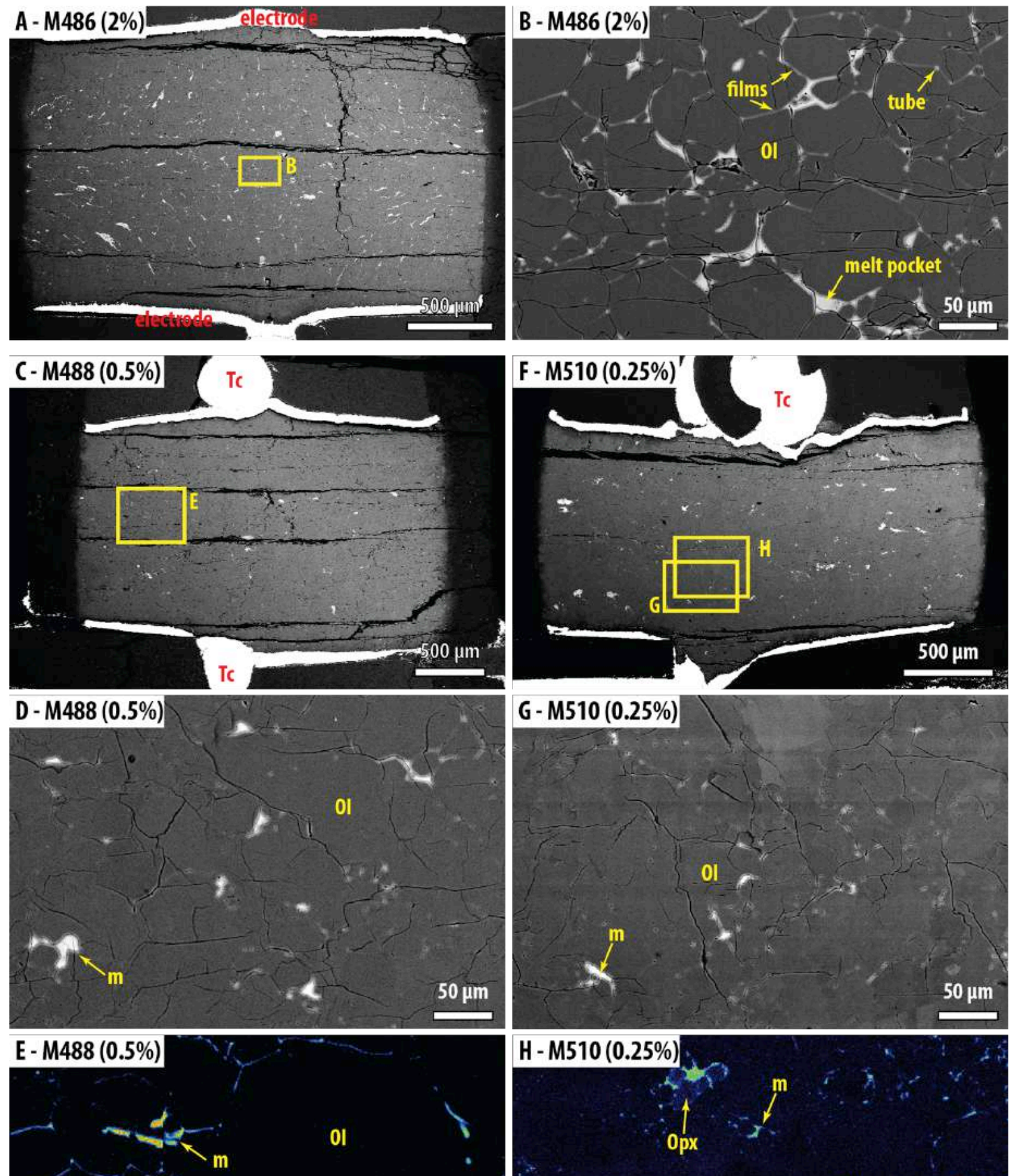

이
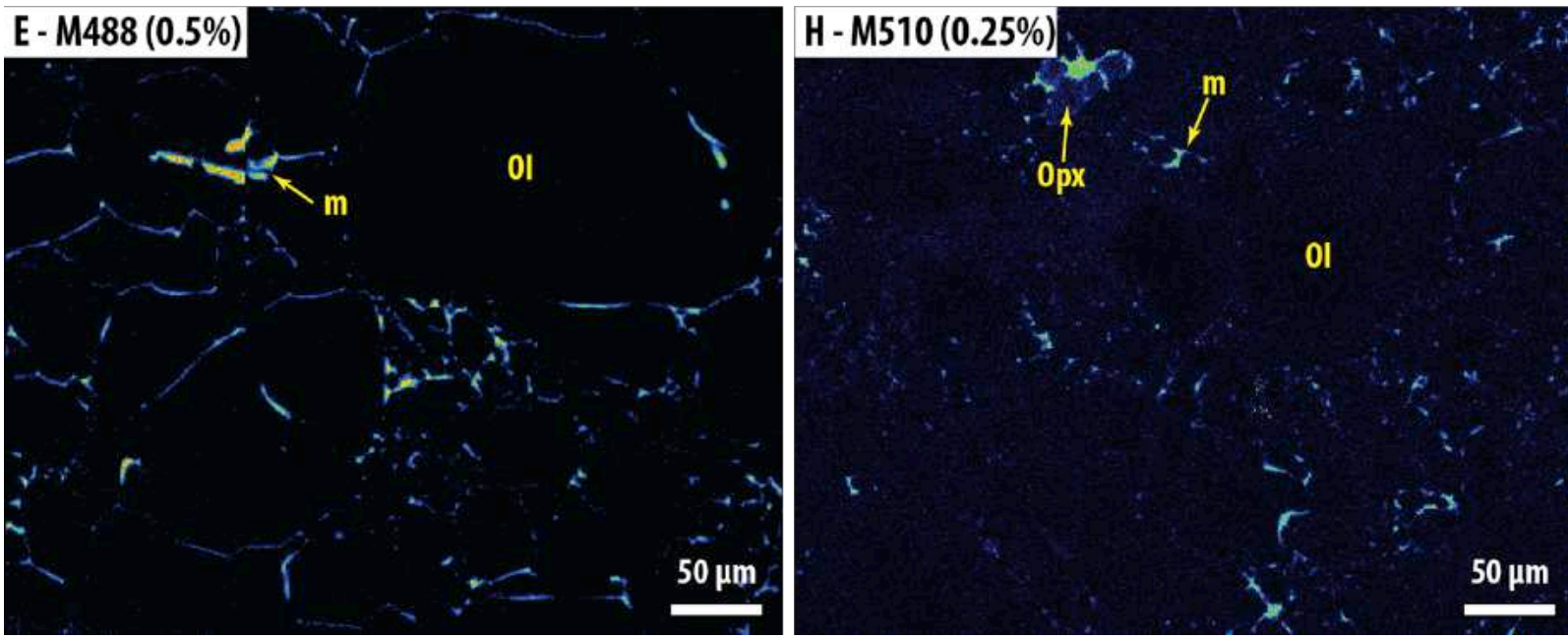

Figure 5: Back-Scattered Electron (BSE) images (A to D, F and G) and relative concentration maps for calcium ( $E$ and $H$ ) in experiments involving $2,0.5$, and 0.25 vol.\% of added basalt. On SEM images, the metal electrodes are white, the melt (m) is light grey and olivine (01) is dark grey. Calcium mapping highlights melt pockets and films around olivine crystals (black and dark blue areas). Rare orthopyroxene crystals (Opx) are present at the top of the sample in image $\mathrm{H}$, coming from impurity in the starting material. 


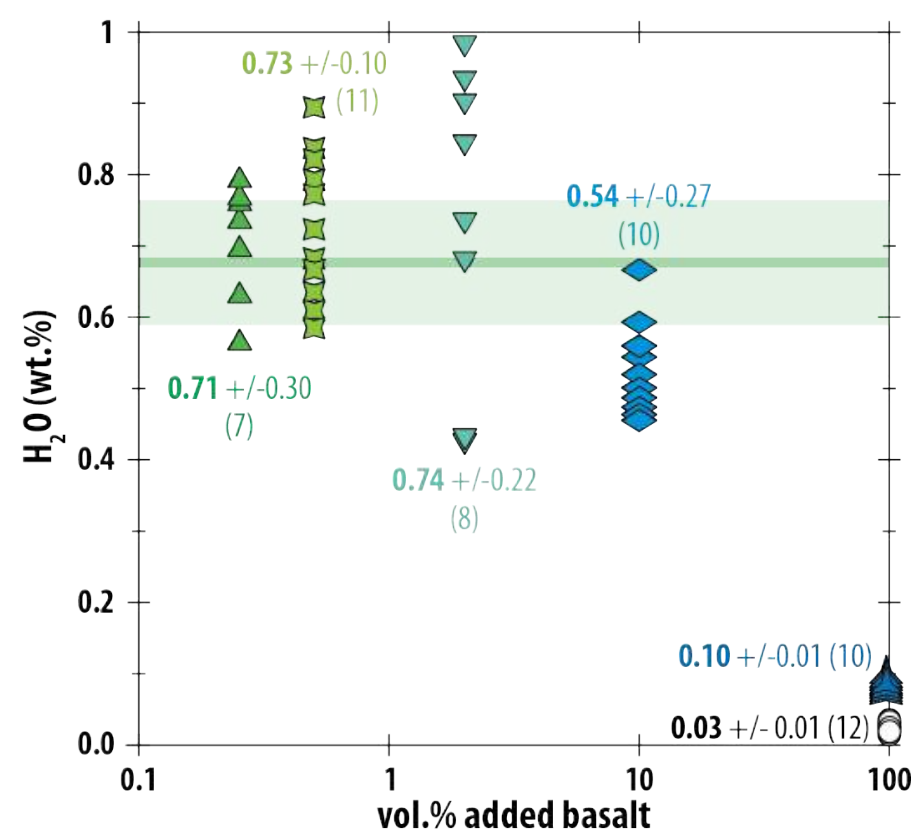

Figure 6: Water contents (bold font) of melts in experimental products reported with the number of analyses (number in brackets). The average water content in melts from experiments with added melt fractions between 0.25 and 0.10 is $0.68 \pm 0.09 \mathrm{wt}$. \% (horizontal green line).

\section{Discussion \\ 4.1. Experimental limitations}

\subsubsection{Chemical contamination}

The experiments were conducted for durations as short as possible (except M523) in order to limit melt loss or chemical contamination of the sample with the surrounding host assembly. Only the experiment conducted with pure basaltic liquid (M480) shows a minor amount of melt percolating into the MgO sleeve (Fig. SI 4 A \& B). Based on the presence of melt after 27 hours at $1319^{\circ} \mathrm{C}$, including regions close to the $\mathrm{MgO}$ sleeve, we believe that there is no significant escape of liquid from the sample over the experimental duration. A stable sample volume and EC measurement is, therefore, maintained over the duration of the experiments. The contamination of the sample by the $\mathrm{MgO}$ sleeve is limited to a narrow peripheral layer of 100 to 150 micrometers in the longest duration experiment (excluding M523), representing less than $5 \%$ of the sample diameter. On the other hand, the platinum electrodes alloy to some degree with iron from olivine and the melt, the latter remaining homogeneous in composition (see iron distribution in the 100\% melt experiment, Fig. SI 4B) except in a narrow $(<50$ microns) layer at the contact with electrodes. This alloying, however, does not influence the electrical conductivity of the sample.

\subsubsection{Textural equilibrium}

Once above the basalt liquidus temperature of the first heating, the EC reaches a value reproduced during later cooling and heating cycles (see the experiment with 0.25 vol.\% of basalt, Fig. 3). According to this observation, we conclude that the melt should have promptly percolated through the sample and wetted the electrodes. The examination of the experiment M523 shows that melt pockets are preserved even after 27 hours without further wetting of the crystal aggregate (Fig. SI 4K \& L). Coaxial strain in the experiments would have favored the percolation of the melt through the aggregate as highlighted by preferentially oriented melt pockets in samples involving 2 and $10 \mathrm{vol} . \%$ of added basalt. The melt distribution geometry in the samples is complex and it is not clear how small amount of coaxial strain would have contributed to enhance the EC in the samples. However, the consistent orientation of these persistent melt pockets parallel to the electrodes (perpendicular to the 
electrical path) should have not led to an increase in the bulk conductivity of the sample (Zhang et al., 2014).

\subsubsection{Melt fraction determination}

The determination of post-experimental melt fractions by SEM observation is challenging due to the image resolution, and the conversion from 2D to 3D. Post-experimental melt fraction estimates are usually under-estimated at low magnification due to the difficulty in observing the thin melt films and pockets, particularly for the samples with the lowest melt fractions (Fig. SI 7). On the other hand, at higher magnification, heterogeneity in melt distribution, i.e. the presence of scattered melt pockets of different sizes, leads to biased estimates of the meltcrystal ratio. This can lead to errors in the melt fraction determination that are larger than the initial mass ratio of the mixed components. Consequently, though the glass fraction observed on post-mortem SEM picture is similar to the one determined from the initial weight ratio of olivine and basalt in the starting material of each experiment, we rely only on the latter (Fig. 5, Fig. SI 4 and Fig. SI 7). In addition, it is possible that the pure olivine aggregate does not remain melt-free at high temperatures (for instance, $\mathrm{T}>1350^{\circ} \mathrm{C}$ ), since the solidus temperature of an olivine aggregate particularly in the presence of even minor amounts of $\mathrm{H}_{2} \mathrm{O}$ could easily be over stepped (Hashim, 2016). However, according to Chantel et al. (2016), the very low amounts of melt that could be expected in the pure olivine aggregate $(<0.1 \%)$ would not wet the grain boundaries, as reflected in the very high EC compared to samples with a low added basalt fraction (Table 2 and Fig. SI 7) even though intergranular mass transport is strongly influenced by minor amounts of hydroxyl as proven by the work of Gardés et al. (2012). It is shown that activation energy of diffusion in hydrous-saturated grain boundaries is reduced compared to dry grain boundaries.

\subsection{Implications of the melt distribution}

For experimental durations investigated in this study ( $<27$ hours), melt pockets are preserved regardless of the melt fraction (Fig. 5), including when the melt is not fully interconnected (melt fraction $<0.5$ vol.\%). Complete redistribution of a small melt fraction appears to require much longer timescales than employed in the experiments. Similar persistent melt pockets were also observed by Garapic et al. (2013) after 430 hours at high temperature. Alternatively, a threshold melt fraction may be required for the complete redistribution of melt pockets, as discussed in the next section. Their stability excludes any textural evolution that would affect the electrical results.

Although tubes are common features in all samples, films on the grain boundaries are not recognized in the samples containing 0.25 vol.\% of added basalt or less (Fig. 5). Such feature seems determinant to switch from a low degree of interconnectivity where films are not present to a high degree of interconnectivity where films are present alongside pockets and tubes. The presence of films implies dihedral angles smaller than $10^{\circ}$ (Cmíral et al., 1998). Our observations therefore suggest that olivine does not exhibit dihedral angles less than $10^{\circ}$ in the presence of very small melt fractions. Furthermore, dihedral angles were observed to be temperature-dependent in melt-bearing olivine aggregates ranging from $19^{\circ}$ to $9^{\circ}$ between $1300^{\circ} \mathrm{C}$ and $1450^{\circ} \mathrm{C}$ (Yoshino et al., 2009). In the olivine-basalt system, the disappearance of films with lower melt fraction seems to record the interconnectivity threshold as supported by the EC measurements (see next section). However, our experimental setup does not allow us to distinguish between the individual effects of pockets or films on the bulk conductivity of the partially molten assemblages.

\subsection{Choice of the mixing law}

The activation energy and pre-exponential factor were determined for each experiment based on an Arrhenius relationship of EC (Eq. 1; Table 2; Fig.4). The calculated EC values closely reproduce the experimental data (Fig. 4). For the pure olivine aggregate, only data points 
obtained at temperatures higher than $1230^{\circ} \mathrm{C}$ were used to determine the fit, corresponding to temperature where ionic conduction is assumed to be the dominant transport mechanism (Fig. 3 and Section 6 of supplementary materials). The value of the EC fitted at $1350^{\circ} \mathrm{C}$ is plotted against the added melt fraction in Figure 7: from 100 down to 0.5 vol.\%, the EC of partially-molten olivine aggregates defines a trend significantly higher than the models commonly used in the literature, such as +Spheres, Tubes, and Cubes models (Grant \& West, 1965; Waff, 1974) (Fig. 7), which can be modeled most closely using the Conventional Archie's law (Eq. 2):

$$
\sigma_{\text {bulk }}=\sigma_{l} \chi_{l}^{m}
$$
where $\sigma_{\text {bulk }}$ is the EC of the system, $\chi_{l}$ the melt fraction in vol. $\%, \sigma_{l}$ the EC of the liquid and $m$ is a measure of how the ratio $\frac{\sigma_{b u l k}}{\sigma_{l}}$ varies as a function of melt fraction and degree of interconnection of the melt (Glover, 2010 and references therein). The value $m$ will be $<2$ for a well-interconnected liquid phase and it will tend to unity only if the liquid phase is fully interconnected and is the only conductive phase (Glover, 2010). In our case, at $1350^{\circ} \mathrm{C}$ and added basalt fraction $>0.5 \mathrm{vol} \%$ (high degree of interconnectivity), the power law exponent $m=0.75 \pm 0.02$ while the first term is the conductivity of the basaltic liquid, i.e. $\log \sigma_{l}=0.89$ $\pm 0.03(\sigma$ in $\mathrm{S} / \mathrm{m})$. This low value of $m$ indicates that the liquid phase is highly interconnected and that another conduction mechanism contributes to the bulk conductivity so as to provide a value of the exponent $m<1$. The existence of another conduction mechanism than the melt is also demonstrated by the higher EC than given by the parallel model ("PM" in Fig. 7), which is supposed to represent the maximum EC where the melt is the unique conduction mechanism.

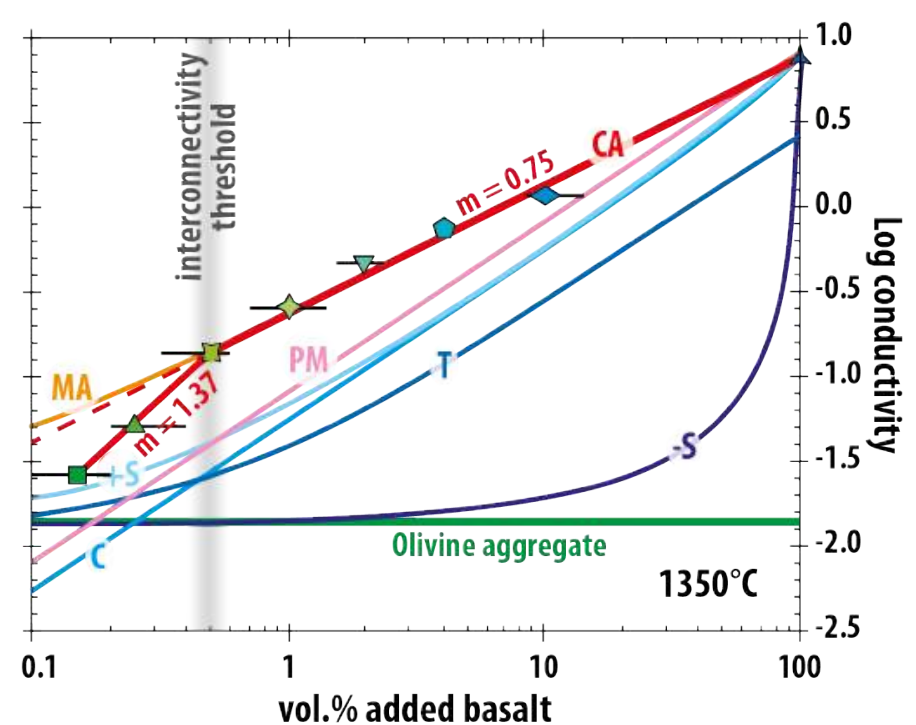

Figure 7: Electrical conductivity versus the fraction of added basalt (in volume \%) (Log scale) from the current experimental data (blue to green symbols which are identical to legend of Fig. 4) compared with the Modified Archie's law (MA), Conventional Archie's law (CA), Parallel model (PM), +Spheres (+S), Cubes (C), Tubes (T) and -Spheres (-S) models (curves) from the literature at $1350^{\circ} \mathrm{C}$. See text for model references. Black segments represent the error on the model fraction estimated by image analysis (see supplementary information).

The maximum value of $m(0.84 \pm 0.05)$ is obtained when considering the experiments with 0.5 to 2 vol. $\%$ of added basalt that contain similar water contents $(\sim 0.68 \pm 0.09$ wt.\%). Based on the experiments of $\mathrm{Ni}$ et al. (2011) at $1450^{\circ} \mathrm{C}$, the effect of $1.1 \mathrm{wt} \%$ of water would increase the EC by $0.3 \log$ unit only ( $\log \sigma=1.0$ ), and the resulting $m$ exponent would be $0.86 \pm 0.04$. Therefore, the value of the exponent $m$ cannot be the result of the small water content difference observed in the experiments. Since the melt composition does not vary 
significantly, in particular in the Na content, the reason why the value of $m$ is lower than unity may reside in the solid phase, even though the EC of the latter is almost 3 log units lower than the basalt melt. Grain boundary effects and/or the existence of an electric double layer (Grahame, 1947) might enhance EC and would argue in favor of a low $m$ exponent after the Na-coating of crystallizing olivine but these concepts cannot be demonstrated by our experiments.

The $m$ value we find is comparable to that (0.89) experimentally determined by Yoshino et al. (2010a), but significantly different from that calculated by Miller et al. (2015) of $1.3 \pm 0.3$. Such a value is inconsistent for melt fractions lower than $0.8 \%$ since the conductivity of the meltbearing olivine aggregate becomes lower than that of olivine-only ( $\log \sigma=-2.05$; Constable, 2006). The exponent calculated by Yoshino et al. (2010a) on an olivine-carbonatite system ( $m$ $=1.14$ ) implies a very good interconnectedness, but the existence of one conducting phase only, probably due to the higher conductivity of carbonatite melt than basaltic one (more than one order of magnitude).

\subsection{Interconnectivity threshold of the melt fraction ( $0.5 \mathrm{vol} . \%)$}

For experiments with added basalt fractions of 0.25 and 0.15 vol.\%, the EC is lower than the trend previously described (dashed line, Fig. 7) but still higher than the olivine-only aggregate defining a higher exponent of $m=1.37$. We deduce that the basaltic melt is no longer fully interconnected but remains still well-interconnected overall, and still contributes to an increase in the bulk EC. Therefore, under our experimental conditions, an interconnectivity threshold exists at a added basalt fraction of 0.5 vol. $\%$ in the olivine aggregates. No mathematical law reproduces such a change in connectedness with the melt fraction. Such a threshold is likely linked to the appearance/disappearance of films, switching to a low/high degree of interconnectivity and resulting in different electrical transport properties. The low degree of interconnectivity is explained by the persistence of tubes in the solid aggregate. The threshold evidenced here occurs at very low melt fraction, and could be easily masked by the high jump in EC observed upon melting observed in other study (e.g. Maumus et al., 2005). The threshold depends on the melt distribution (tubes / films...), thus on the wetting properties of the melt with the solid phase (Yoshino et al. 2009; Zhu et al. 2011).

\subsection{Model of the EC of partially-molten olivine aggregate}

Since the difference between the conventional and the modified Archie's laws is negligible above the interconnectivity threshold (added basalt fraction $\sim 0.5$ vol.\%), we use the conventional law to fit all data from this study with a high degree of interconnectivity: we now incorporate the temperature dependence on the EC to the previous fit by regressing the evolution of the Archie's law parameters with temperature. The correlation of the two parameters with temperature provides the following simplified equation:

$$
\log \sigma=(a T+b) * \log \chi_{m}+(c T+d)
$$
where $\sigma, \mathrm{T}, \chi_{m}$ are the electrical conductivity (in S/m), the temperature (in Kelvin) and the melt fraction respectively, and $a$ to $d$ are fitting parameters determined from the experiments $(a=3.66 E-04 \pm 8 E-6 ; b=0.151 \pm 0.013 ; c=4.52 E-03 \pm 1 E-4 ; d=-6.448 \pm 0.16)$. The mixing model integrating both temperature and melt fraction is valid for temperatures higher than $1230^{\circ} \mathrm{C}$ and melt fractions $\chi_{m}$ higher than 0.5 vol.\%.

The same Equation 3 can be applied to fit calculate the EC of partially molten olivine aggregate with melt fraction ranging between 0.5 down to $0.15 \mathrm{vol} . \%$ and temperature higher than $1230^{\circ} \mathrm{C}$. In that case, the fitting parameters are $a^{\prime}=1.57 \mathrm{E}-04 \pm 4 E-6 ; b^{\prime}=1.113 \pm 0.006 ; c^{\prime}=$ $3.92 E-03 \pm 9 E-5 ; d^{\prime}=-4.082 \pm 0.14$. In this range of melt fraction with a lower degree of connectivity, if $\mathrm{m}=1.37$, then the preexponential factor $\mathrm{A}=2.9 \log$ units, being a value too high for the conductivity of basaltic melt. Hence, there must be other phase more conductive 
than olivine to get $m=1.37$, such as, for instance, grain boundary effects that become more and more significant at lower melt fractions (Marquardt et al., 2015).

Both models reproduce very closely the experimental results (see Fig. SI 8) and is compared with data from the literature (Fig. 8) except the solid end-member for which the Arrhenius fit is used (Eq. 1; Table 2).

Conductivities for both solid and liquid end-members fall in the range of their respective values defined by previous studies, though most of the melt measurements were performed on basaltic liquids that do not appear to respect an Arrhenius law (Fig. 8) (Presnall, 1972; Waff \& Weill, 1975; Tyburczy \& Waff, 1983; Pommier et al., 2010; Ni et al., 2011). The EC measurements on the pure olivine aggregate reproduce closely those reported for olivine by Poe et al. (2010) along the (100) and (001) axis orientations at lower temperatures ( $\mathrm{T}<$ $1250^{\circ} \mathrm{C}$ ) but the data diverge quite significantly at higher temperatures. A comparison between our measurements and those reported for dry olivine and olivine containing $50 \mathrm{ppm}$ of $\mathrm{H}_{2} \mathrm{O}$ (Jones et al., 2012) is consistent with SIMS analyses indicating $<10 \mathrm{ppm} \mathrm{H}_{2} \mathrm{O}$ in our olivine aggregates. Caution should be taken, however, when comparing transport mechanisms determined for single crystals, with those of polycrystalline aggregates since models for this conversion have not be thoroughly tested. Finally, the extrapolation of olivine EC measured at low temperature (typically $<1200^{\circ} \mathrm{C}$ ) to natural upper mantle conditions by assuming a constant $\mathrm{E}_{\mathrm{a}}$ may be misleading, in particular at low melt fractions and high temperatures where the contribution of olivine to EC is significant.

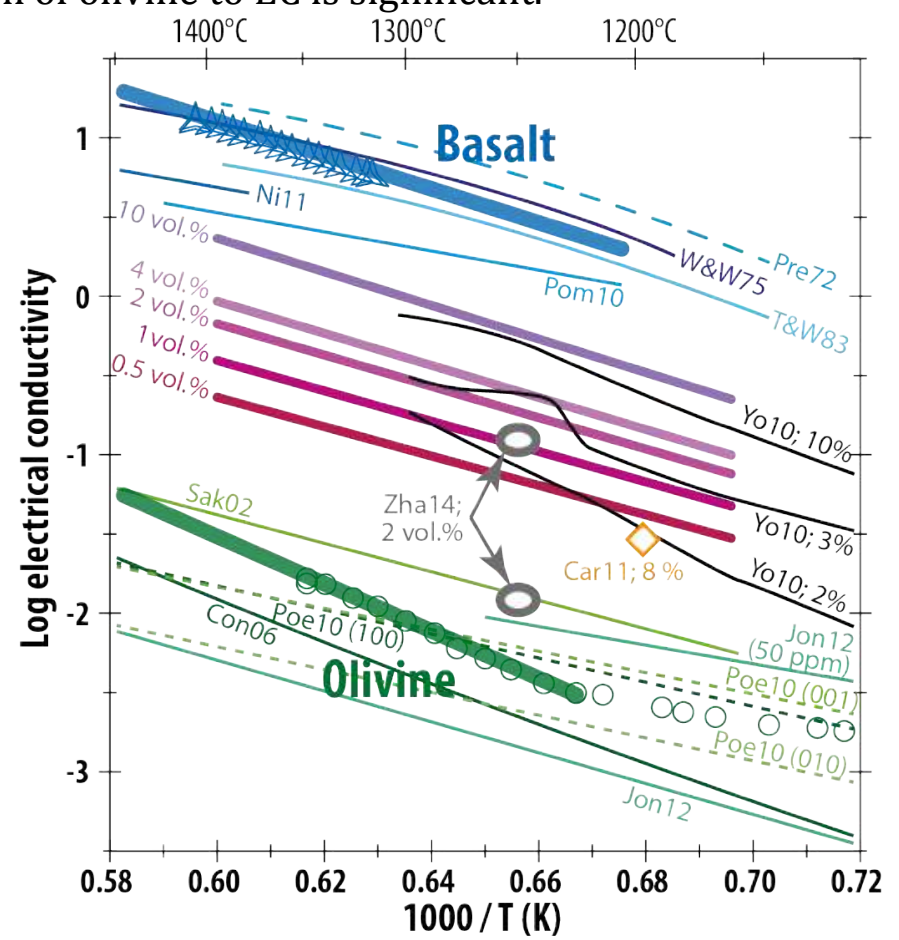

Figure 8: Electrical conductivity plotted against the reciprocal temperature for basalt, olivine aggregate and partially molten olivine aggregates with various fractions of basalt. Thick curves are model endmember conductivities (basalt and olivine aggregate), plotted with the experimental data (3 point stars and circles respectively). Modeled mixtures from this study (purple to pink) are also shown. Previous studies on basalt with comparable compositions are shown as thin blue curves (Presnall, 1972; Waff \& Weill, 1975; Tyburczy \& Waff, 1983; Pommier et al., 2010; Ni et al., 2011), whereas previous olivine measurements are shown by thin green curves (Sakamoto et al., 2002; Constable, 2006; Poe et al., 2010; Jones et al., 2012) and partially molten olivine aggregate measurements (Yoshino et al., 2010; Caricchi et al., 2011; Zhang et al., 2014). The two values from Zhang et al (2014) correspond to measurement in the direction normal (lower value) and parallel (higher value of conductivity) to the shear direction. Melt proportions from Yoshino et al. (2010a) and Caricchi et al. (2011) are expressed in weight \%. 
The comparison of the EC of partially molten olivine aggregate with the study of Yoshino et al. (2010a) (10, 3 and 2 wt.\% of basalt added to olivine aggregate), corresponding to volume proportions of 8, 2.4 and 1.6 vol.\% when assuming densities of 3.3 for olivine and 2.7 for the basalt), show similar values at $\mathrm{T}<1300^{\circ} \mathrm{C}$, but the higher $\mathrm{E}_{\mathrm{a}}$ they found and the presumed absence of water in their experimental products results in lower EC at higher temperatures (Fig. 8). One significant difference between the two studies is the starting grain size (up to 100 micrometers here against a few micrometers in Yoshino et al., 2010a). Our model also gives a higher conductivity than deformed partially-molten olivine aggregates (Caricchi et al., 2011; Zhang et al., 2014). In the study of Zhang et al. (2014), the electrical anisotropy of a peridotite with 2 vol.\% of basaltic melt is investigated during deformation. The EC in the direction parallel to the shear direction is one order higher than in the one normal to the shear plane. Such a difference comes from the good melt interconnection and agrees with our results (Fig. 8). In addition, the EC value of the experiment with 2 vol.\% of added melt lowered by one order of magnitude would provide a melt fraction close to 0.25 vol.\%, therefore in the field of low degree of interconnectivity, such as suggested by Zhang et al. (2014).

\subsection{Estimation of the melt fraction in the upper mantle}

\subsubsection{Oceanic asthenosphere}

Our model for the EC of melt-bearing olivine aggregates can be adapted for the interpretation of melt-induced electrical anomalies located in the upper mantle, in situations where (i) the melt is likely basaltic in composition and exceeds 0.15 vol.\%, (ii) assuming the EC of peridotite is similar to that of an olivine aggregate, (iii) the grain size has negligible effect on the EC and (iv) regions are deformed by long-range tectonic stresses. The absence of a measureable pressure effect on the EC between 1.5 and $3.0 \mathrm{GPa}$ implies that the mixing model developed in this study can be applied to understand the conductivity structures of the LAB and LVZ. Our model implies an interpreted maximum melt fraction of $0.4-1$ vol.\% to explain the conductive, off-axis region of the East Pacific Rise (off EPR), assuming a temperature of $1350^{\circ} \mathrm{C}$ (Evans et al., 2005; Baba et al., 2006; Sarafian et al., 2015) (Fig. 9A). The lower EC of the Cocos plate $\mathrm{LAB}(\log \sigma=-0.6$ to $-0.9 \mathrm{~S} / \mathrm{m})$ and higher assumed temperature $\left(1420^{\circ} \mathrm{C}\right.$; Naif et al., 2013) leads to a melt fraction range of 0.3 to 0.5 vol. $\%$, implying that the melt would not be fully interconnected (Fig. 9A). These melt proportions estimated for the top of the asthenosphere in these two regions are lower than previous estimates (e.g. Evans et al., 1999, 2005; Baba et al., 2006; Hirschmann, 2010; Yoshino et al., 2010a; Ni et al., 2011; Naif et al., 2013) as a result of the mathematical models previously employed underestimating bulk EC at low melt fractions. On the other hand, the melt fractions remotely estimated using our model agree with estimates of $<1 \%$ based on melt migration and incremental melting models, in which there is a maximum melt fraction that can be retained by the solid matrix (Kelemen et al., 1997). They also agree to the value of 0.5 vol.\% estimated by Chantel et al (2016) based on ultrasound velocity measurements.

\subsubsection{East-Pacific Rise and Mid-Ocean Ridge regions}

The melt fraction estimated beneath the EPR crest will depend strongly on the solidus of the peridotite and, therefore, on the adiabatic gradient. We use a melting depth interval of between 60 and $100 \mathrm{~km}$ (Langmuir et al., 1993; Baba et al., 2006; Key et al., 2013) and employ the volatile-poor peridotite solidus determined by Hirschmann (2000) (Fig. 9B) to constrain the pressure (2 to $3 \mathrm{GPa}$ ) and temperature $\left(1330\right.$ to $1400^{\circ} \mathrm{C}$ ) of the melting zone beneath the EPR. Under such conditions, based on the conductivity value of Baba et al. (2006) and our results, we estimate melt proportions of between 0.8 and 4 vol.\%, which is consistent with the value of Kelemen et al. (1997, and references therein), although less than half the value of $10 \%$ proposed by Key et al. (2013). 
Contrary to the suggestion of Miller et al. (2015), high concentrations of volatiles in the melt $(>0.7 \mathrm{wt} \%)$ and olivine aggregate are not required to explain conductive anomalies in the oceanic upper mantle, under ridge or at the top of the asthenosphere. However, higher concentrations of volatiles dissolved in the melt would significantly increase the bulk conductivity (Gaillard 2004; Ni et al., 2011; Sifré et al., 2014; Laumonier et al., 2015) and the temperature, melt fraction and volatile concentration would be highly correlated. It therefore becomes impossible to resolve between the effects of temperature or volatile concentration using EC alone and some additional constraint needs to be found, a problem that is beyond the scope of this study.

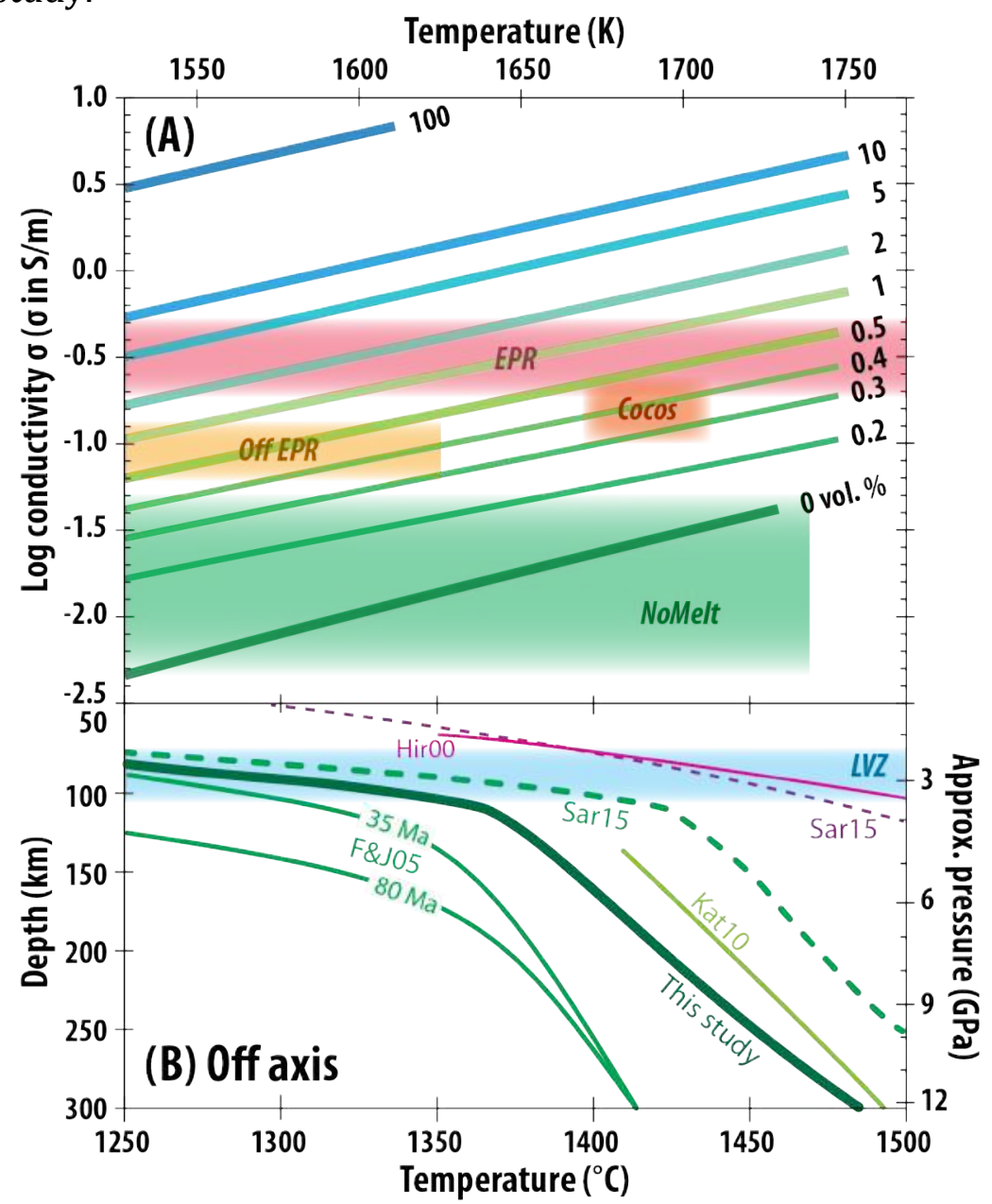

\subsection{Temperature estimation of the "NoMelt" upper mantle}

Sarafian et al. (2015) reported the EC structure beneath the 70 Ma Pacific plate, located between the Clarion and Clipperton fracture zones where no melt should be present ("NoMelt" experiment). We estimate the temperature distribution of this site using our olivine-only sample conductivity and assuming the absence of melt and significant proportions of volatiles in constituting mantle minerals (Fig. 9A \& B). The resulting 
temperature increases almost linearly from $70\left(1265^{\circ} \mathrm{C}\right)$ to $110 \mathrm{~km}\left(1362^{\circ} \mathrm{C}\right)$ and from 110 to $300 \mathrm{~km}\left(1486^{\circ} \mathrm{C}\right)$ with gradients of $\sim 5^{\circ} / \mathrm{km}$ and $0.65^{\circ} \mathrm{C} / \mathrm{km}$ respectively. The temperature profile is about $50^{\circ} \mathrm{C}$ lower than the geotherm estimated by Sarafian et al. (2015) that was based on the EC of olivine after Constable (2006); it is similar to that of Katsura et al. (2010) and significantly higher than that proposed by Faul \& Jackson (2005) from fitting the shear modulus and attenuation data obtained experimentally on olivine Fo90. The geotherm we calculate implies a temperature difference by about $100^{\circ} \mathrm{C}$ from the solidus of dry peridotite (e.g. Hirschmann, 2000; Sarafian et al., 2015). Such a temperature difference excludes the presence of dry, silicate melt in those regions.

\subsection{Melt interconnectivity and mobility}

The 0.5 to $1 \%$ of melt estimated using our model to explain the magnitude of the electrical anomaly at the top of the asthenosphere would have a high degree of interconnectivity but unable to segregate upwards only based on the absence of intense volcanism at the surface. On the contrary, the melt produced beneath a Mid-Ocean Ridge (MOR) rises upwards due to a buoyancy effect, which implies the existence of a minimum permeability threshold for melt ascent in the production of MOR-Basalt, consistent with the efficient draining of the mantle at melt fraction higher than 1\% (Zhu et al., 2011). The permeability significantly increases between $0.5-1$ vol.\% (LVZ) and 0.8-4 vol.\% (beneath MOR) without taking into account the anisotropic distribution of the melt. This melt fraction interval corresponds to a permeability $k\left(\mathrm{~m}^{2}\right)$ bounded between $\log k=-16.7$ (at 0.5 vol.\% of melt) and $k=-14.3$ (melt fraction of 4 vol.\%) based on Miller et al. (2014). The permeability calculated for a 4 vol.\% melt fraction corresponds to a compaction length of the order of $70 \mathrm{~km}$ for a MORB-like melt at $1350^{\circ} \mathrm{C}$ (McKenzie, 1985), which matches the thickness of the layer the melt has to percolate beneath EPR axis.

The critical melt fraction (melt fraction above which melt is drained through the network, Holtzman, 2016) may thus range between the melt fraction of the LVZ (sustainable melt in the mantle) and the one of intense melt production beneath the MOR. According to our results, such a critical melt fraction in the high conductivity regions ranges between 0.5 and 1 vol.\% in volume, significantly higher than $0.1 \%$ estimated by Hirschmann (2010). As suggested by Miller et al. (2015), electrical and fluid flow pathways may act differently. The critical melt fraction may also depend on the local and regional stress field. We also still lack knowledge concerning the melt distribution (pervasive or scattered) in natural settings either beneath the MOR or at the LAB. Furthermore, anisotropic distribution of silicate melts may also significantly increase EC (Pommier et al., 2015a). The presence of "petit spot" volcanoes within the oceanic crust might result from localized melt concentrations higher than the critical melt fraction (about 1\%) after eventual accumulation, that are thus synonymous with non-pervasive melt distribution in the LVZ, which does not require a formation mechanism that directly involves oceanic plate flexure (Hirano et al., 2006; Yamamoto et al., 2014).

\section{Conclusions}

The results of our in situ electrical conductivity measurements allow us to build a model for the electrical conductivity of partially molten olivine aggregates as a function of temperature $\left(\mathrm{T}>1230^{\circ} \mathrm{C}\right)$ and melt fraction $(0.15$ to 100 vol.\%) based on the conventional Archie's Law. The low value of the exponent $m\left(0.75\right.$ at $1350^{\circ} \mathrm{C}$ and melt fraction higher than 0.5 vol.\%) suggests that the conductivity of partially-molten olivine aggregate operates through several mechanisms, the main one being achieved by the presence of melt. High volatiles concentrations anisotropic distribution of the melt are not necessarily required in order to explain high conductivities observed in upper mantle setting: we interpret the upper asthenosphere electrical anomaly to result from the presence of 0.5 to 1 vol.\% of melt, which 
is consistent with the persistence of melt at depths. On the other hand, the conductivity of regions beneath MOR results from the presence of higher amounts of melt $(<4$ vol.\%) that ascend towards the crust, thus defining a percolation threshold. Since relatively high concentrations of $\mathrm{H}_{2} \mathrm{O}$ and/or $\mathrm{CO}_{2}$ have been suggested to be present in the upper mantle (leading to carbonatite melt for the case of $\mathrm{CO}_{2}$ ), our model and conclusions should also be tested on hydrous peridotite and/or carbonatitic melts (Dasgupta et al., 2013; Sifre et al., 2014), as well as the effect of grain size and thus grain boundary effect on the electrical conductivity, which might be tested using the approach of Marquardt et al. (2015).

\section{Acknowledgements}

ML was supported by the Alexander von Humboldt Foundation and the free state of Bavaria. KM acknolwdges supported by the German Research Foundation (DFG) with grant no MA 6278/2-1 and grant no MA 6278/3-1. We thank H. Keppler, F. Heidelbach, G. Manthilake and E. Gardés for fruitful discussions and the constructive comments from 2 anonymous reviewers. This work would not have been possible without the technical skills of H. Fischer, D. Krausse, R. Njul, H. Schulze and S. Übelhack.

\section{References (55)}

Baba, K., Chave, A. D., Evans, R. L., Hirth, G., \& Mackie, R. L. (2006). Mantle dynamics beneath the East Pacific Rise at $17 \mathrm{~S}$ : Insights from the Mantle Electromagnetic and Tomography (MELT) experiment. Journal of Geophysical Research: Solid Earth (1978-2012), 111(B2).

Barsoukov, E., \& Macdonald, J. R. (Eds.). (2005). Impedance spectroscopy: theory, experiment, and applications. John Wiley \& Sons.

Caricchi, L., Gaillard, F., Mecklenburgh, J., \& Le Trong, E. (2011). Experimental determination of electrical conductivity during deformation of melt-bearing olivine aggregates: implications for electrical anisotropy in the oceanic low velocity zone. Earth and Planetary Science Letters, 302(1), 81-94.

Chantel, J., Mahtilake, G., Andrault, D., Novella, D., Yu, T., Wang, Y. (2016). Experimental evidence supports mantle partial melting in the asthenosphere. Science Advances 2, e1600246.

Cmíral, M., Gerald, J. D. F., Faul, U. H., \& Green, D. H. (1998). A close look at dihedral angles and melt geometry in olivine-basalt aggregates: a TEM study. Contributions to Mineralogy and Petrology, 130(3-4), 336-345.

Constable, S. (2006). SE03: a new model of olivine electrical conductivity. Geophysical Journal International, 166(1), 435-437.

Dai, L., Karato, S. (2014). High and highly anisotropic electrical conductivity of the asthenosphere due to hydrogen diffusion in olivine. Earth and Planetary Science Letter 408, 79-86.

Dasgupta, R., Mallik, A., Tsuni, K., Withers, A.C., Hirth, G., Hirschmann, M.M. (2013). Carbon-dioxide-rich silicate melt in the Earth's upper mantle. Nature 493, 211-215.Evans, R. L., Hirth, G., Baba, K., Forsyth, D., Chave, A., \& Mackie, R. (2005). Geophysical evidence from the MELT area for compositional controls on oceanic plates. Nature, 437(7056), 249-252.

Faul, U. H. (1997). Permeability of partially molten upper mantle rocks from experiments and percolation theory. Journal of Geophysical Research: Solid Earth, 102(B5), 10299-10311.

Faul, U. H., \& Jackson, I. (2005). The seismological signature of temperature and grain size variations in the upper mantle. Earth and Planetary Science Letters, 234(1), 119-134.

Faul, U. H., \& Scott, D. (2006). Grain growth in partially molten olivine aggregates. Contributions to Mineralogy and Petrology, 151(1), 101-111.

Gaillard, F. (2004). Laboratory measurements of electrical conductivity of hydrous and dry silicic melts under pressure. Earth and Planetary Science Letters, 218(1), 215-228.

Gaillard, F., Malki, M., Iacono-Marziano, G., Pichavant, M., Scaillet, B. (2008). Carbonatite melts and electricl conductivity in the asthenosphere. Science 322 (5906), 1363-1365.

Garapić, G., Faul, U.H., Brisson, E. (2013). High-resolution imaging of the melt distribution in partially molten upper mantle rocks: evidence for wetted two-grain boundaries. Geochemistry, Geophysics, Geosystems 14 (3), 556- 566. doi:10.1029/2012GC004547.

Gardés, E., Wunder, B., Marquardt, K., \& Heinrich, W. (2012). The effect of water on intergranular mass transport: new insights from diffusion-controlled reaction rims in the $\mathrm{MgO}-\mathrm{SiO} 2$ system. Contributions to Mineralogy and Petrology, 164(1), 1-16.

Gardés, E., Gaillard, F., \& Tarits, P. (2014). Toward a unified hydrous olivine electrical conductivity law. Geochemistry, Geophysics, Geosystems, 15(12), 4984-5000.

Glover, P.W.J. (2010). A generalized Archie's law for n phases. Geophysics 75 (6), E247-E265. 
Grant, F. S., and G. F. West (1965). Introduction to the electrical methods, in Interpretation Theory in Applied Geophysics, edited by R. R. Shrock, pp. 385-401, McGraw-Hill, New York.

Grahame, D. C. (1947). The electrical double layer and the theory of electrocapillarity. Chemical reviews, 41(3), 441-501.

Hashim, L. (2016). Unraveling the grain size evolution in the Earth's upper mantle. University of Orleans, PhD, 124 pp.

Hirano, N., Takahashi, E., Yamamoto, J., Abe, N., Ingle, S. P., Kaneoka, Hirata, T., Kimura, I.J., Ishii, T., Ogawa, Y., Machida, S., Suyehiro, K. (2006). Volcanism in response to plate flexure. Science, 313(5792), 1426-1428.

Hirschmann, M. M. (2000). Mantle solidus: experimental constraints and the effects of peridotite composition. Geochemistry, Geophysics, Geosystems, 1(10).

Hirschmann, M. M. (2006). Water, melting, and the deep Earth H2O cycle. Annual Review of Earth and Planetary Science 34, 629-653.

Hirschmann, M. M. (2010). Partial melt in the oceanic low velocity zone. Physics of the Earth and Planetary Interiors, 179(1), 60-71.

melt fraction in the asthenosphere. Geochemistry, Geophysics, Geosystems, 17(2), 470-484.

Huebner, J.S., Macdonald, R.G. (1995). Impedance spectra of hot, dry silicate minerals and rock: qualitative interpretation of spectra. American Mineralogist 80 (1-2), 46-64.

Holtzman, B.K. (2016). Questionson the existence, persistence and mechanical effects of a very small melt fraction in the astenoshpere. Geochemestry, Geophysics, Geosystems 17 (2), 470-484

Jones, A. G., Fullea, J., Evans, R. L., \& Muller, M. R. (2012). Water in cratonic lithosphere: Calibrating laboratorydetermined models of electrical conductivity of mantle minerals using geophysical and petrological observations. Geochemistry, Geophysics, Geosystems, 13(6).

Kelemen, P. B., Hirth, G., Shimizu, N., Spiegelman, M., \& Dick, H. J. (1997). A review of melt migration processes in the adiabatically upwelling mantle beneath oceanic spreading ridges. Philosophical Transactions of the Royal Society of London A: Mathematical, Physical and Engineering Sciences, 355(1723), 283-318.

Key, K., Constable, S., Liu, L., \& Pommier, A. (2013). Electrical image of passive mantle upwelling beneath the northern East Pacific Rise. Nature, 495(7442), 499-502.

Langmuir, C. H., Klein, E. M., \& Plank, T. (1993). Petrological systematics of mid-ocean ridge basalts: Constraints on melt generation beneath ocean ridges. Mantle flow and melt generation at mid-ocean ridges, 183-280.

Laumonier, M., Gaillard, F., Sifre, D. (2015). The effect of pressure and water concentration on the electrical conductivity of dacitic melts: Implication for magnetotelluric imaging in subduction areas. Chemical Geology 418, 66-76. doi:10.1016/j.chemgeo.2014.09.019.

Manthilake, M.A.G.M., Walte, N., Frost, D.J. (2012). A new multi-anvil press employing six independently acting 8 MN hydraulic rams. High pressure research: an international journal. DOI:10.1080/08957959.2012.680450.

Marquardt, K., Rohrer, G. S., Morales, L., Rybacki, E., Marquardt, H., \& Lin, B. (2015). The most frequent interfaces in olivine aggregates: the GBCD and its importance for grain boundary related processes. Contributions to Mineralogy and Petrology 170(4), 40.

Maumus, J., Bagdassarov, N., \& Schmeling, H. (2005). Electrical conductivity and partial melting of mafic rocks under pressure. Geochimica et Cosmochimica Acta, 69(19), 4703-4718.

McKenzie, D. (1985). The extraction of magma from the crust and the mantle. Earth and Planetary Science Letters 74, 81-91.

Miller, K. J., Zhu, W. L., Montési, L. G., \& Gaetani, G. A. (2014). Experimental quantification of permeability of partially molten mantle rock. Earth and Planetary Science Letters, 388, 273-282.

Miller, K. J., Montési, L. G., \& Zhu, W. L. (2015). Estimates of olivine-basaltic melt electrical conductivity using a digital rock physics approach. Earth and Planetary Science Letters, 432, 332-341.

Naif, S., Key, K., Constable, S., \& Evans, R. L. (2013). Melt-rich channel observed at the lithosphere-asthenosphere boundary. Nature, 495(7441), 356-359.

Ni, H., Keppler, H., \& Behrens, H. (2011). Electrical conductivity of hydrous basaltic melts: implications for partial melting in the upper mantle. Contributions to Mineralogy and Petrology, 162 (3), 637-650.

Poe, B., Romano, C., Nestola, F., Smyth, J.R., (2010a). Electrical conductivity anisotropy of dry and hydrous olivine at $8 \mathrm{GPa}$. Physics of the Earth and Planetary Interiors 181, 103-111.

Pommier, A., Gaillard, F., \& Pichavant, M. (2010). Time-dependent changes of the electrical conductivity of basaltic melts with redox state. Geochimica et Cosmochimica Acta, 74(5), 1653-1671.

Pommier, A., Leinenweber, K., Kohlstedt, D.L., Qi, C., Garnero, E.J, Mackwell, S.J., Tyburczy, J.A. (2015a). Experimental constraints on the electrical anisotropy of the lithosphere-asthenosphere system. Nature $\mathbf{5 2 2}$. DOI:10.1038/nature14502.

Pommier, A., Leinenweber, K., \& Tasaka, M. (2015b). Experimental investigation of the electrical behavior of olivine during partial melting under pressure and application to the lunar mantle. Earth and Planetary Science Letters, 425, 242-255.

Presnall, D. C., Simmons, C. L., \& Porath, H. (1972). Changes in electrical conductivity of a synthetic basalt during melting. Journal of Geophysical Research, 77(29), 5665-5672. 
Roberts, J.J., Tyburczy, J.A, (1999). Partial-melt electrical conductivity: influence of melt composition. Journal of Geophysical Research, Solid Earth 104 (B4), 7055-5065. DOI:10.1029/1998JB900111.

Sakamaki, T., Suzuki, A., Ohtani, E., Terasaki, H., Urakawa, S., Katayama, Y., ... \& Ballmer, M. D. (2013). Ponded melt at the boundary between the lithosphere and asthenosphere. Nature Geoscience, 6(12), 1041-1044.

Sakamoto, D., Yoshiasa, A., Yamanaka, T., Ohtaka, O., Ota, K. (2002). Electric conductivity of olivine under pressure investigated using impedance spectroscopy. Journal of Physics: Condensed Matter 14, 11375-11379.

Sarafian, E., Evans, R., Collins, J. A., Elsenbeck, J., Gaetani, G. A., Gaherty, J. B., ... \& Lizarralde, D. (2015). The electrical structure of the central Pacific upper mantle constrained by the NoMelt experiment. Geochemistry, Geophysics, Geosystems, 16(4), 1115-1132.

Sifré, D., Gardès E., Massuyeau, M., Hashim, L., Hier-Majumder, S., Gaillard, F. Electrical conductivity during incipient melting in the oceanic low-velocity zone. Nature 509, 81-85.

Ten Grotenhuis, S. M., Drury, M. R., Spiers, C. J., \& Peach, C. J. (2005). Melt distribution in olivine rocks based on electrical conductivity measurements. Journal of Geophysical Research: Solid Earth, 110(B12).

Tyburczy, J. A., \& Waff, H. S. (1983). Electrical conductivity of molten basalt and andesite to 25 kilobars pressure: Geophysical significance and implications for charge transport and melt structure. Journal of Geophysical Research: Solid Earth (1978-2012), 88(B3), 2413-2430.

Tyburczy, J. A., Fisler, D. K. (1995). Electrical properties of minerals and melts. Mineral Physics and Crystallography, A Handbook of Physical Constants, 185-208.

Waff, H. S. (1974). Theoretical considerations of electrical conductivity in a partially molten mantle and implications for geothermometry. J. Geophys. Res. 79(26), 4003-4010.

Waff, H. S., \& Weill, D. F. (1975). Electrical conductivity of magmatic liquids: effects of temperature, oxygen fugacity and composition. Earth and Planetary Science Letters, 28(2), 254-260.

Wanamaker, B.J., Duba, A.G. (1993). Electrical conductivity of San Carlos olivine along [100] under oxygen- and pyroxene-buffered conditions and implications for defect equilibria. Journal of Geophysical Research 98(B1), 489-500.

Yamamoto, J., Korenaga, J., Hirano, N., \& Kagi, H. (2014). Melt-rich lithosphere-asthenosphere boundary inferred from petit-spot volcanoes. Geology, 42(11), 967-970.

Yang, X. (2012). Orientation-related electrical conductivity of hydrous olivine, clinopyroxene and plagioclase and implication for the structure of the lower continental crust and uppermost mantle. Earth and Planetary Science Letter 317-318, 241-250.

Yoshino, T., Yamazaki, D., Mibe, K. (2009). Well-wetted olivine grain boundaries in partially molten peridotite in the asthenosphere. Earth and Planetary Science letters 283, 167-173.

Yoshino, T., Laumonier, M., McIsaac, E., \& Katsura, T. (2010a). Electrical conductivity of basaltic and carbonatite melt-bearing peridotites at high pressures: Implications for melt distribution and melt fraction in the upper mantle. Earth and Planetary Science Letters, 295(3), 593-602.

Yoshino, T. \& Katsura, T. (2010b). Electrical conductivity of mantle minerals: role of water in conductivity anomalies. Annual Review of Earth and Planetary Sciences, DOI:10.1146/annurev-earth-050212-124022.

Yoshino, T., McIsaac, E., Laumonier, M., \& Katsura, T. (2012). Electrical conductivity of partial molten carbonate peridotite. Physics of the Earth and Planetary Interiors 194, 1-9.

Yoshino, T., \& Katsura, T. (2013). Electrical conductivity of mantle minerals: role of water in conductivity anomalies. Annual review of earth and planetary sciences, 41, 605-628.

Zhang, B., Yoshino, T., Yamazaki, D., Manthilake, G., \& Katsura, T. (2014). Electrical conductivity anisotropy in partially molten peridotite under shear deformation. Earth and Planetary Science Letters, 405, 98-109.

Zhu, W., Gaetani, G. A., Fusseis, F., Montési, L. G., \& De Carlo, F. (2011). Microtomography of partially molten rocks: three-dimensional melt distribution in mantle peridotite. Science, 332(6025), 88-91. 


\section{Experimental determination of melt interconnectivity and} electrical conductivity in the upper mantle

\section{Supplementary Information}

\section{Mg contamination from the MgO sleeve}

To avoid electrical short cut, the sample cannot be surrounded by a metallic capsule. A MgO sleeve was chosen to replace any common capsule with limited chemical contamination. The longest experiments with temperature variation (M488) lasted more than 6 hours including 5 hours at temperature between 1000 and 1373. The contact between the MgO sleeve and the sample is still sharp, despite a halo of $\sim 200$ micrometers (Fig. SI 1). The contamination consists in the enrichment in magnesium in the sample periphery and in iron in its container. The boundaries of olivine crystal in the contaminated zone looks darker (aka MgO-enriched) areas. Other experiments conducted for shorter times at similar temperatures display thinner contaminated sample.

19

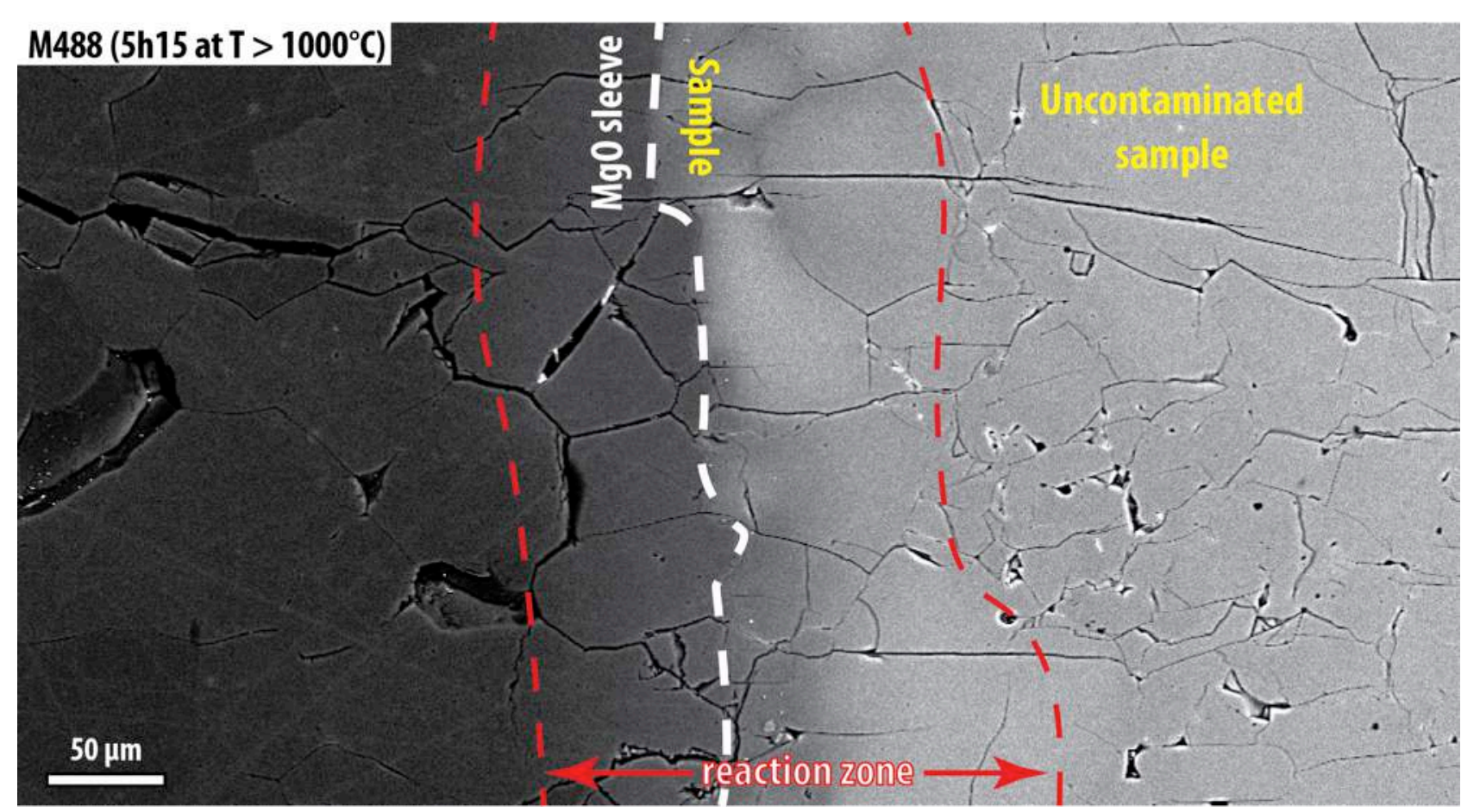

Fig. SI 1: SEM image of the sample periphery in contact with the MgO sleeve. Contamination (MgO from the sleeve to the sample, mostly iron from the sample to the sleeve) operated over a $\sim 200$-micrometer thick reaction zone. 


\section{2-/4-wire set up}

We examine in the following way whether the circuit resistance is low enough to measure our sample, keeping in mind that basaltic liquid should have a high conductivity. During a test run, a short circuit happened preventing us to measure the sample resistance. Nonetheless, we examined the resistance of the electric cell alternating the 2-and 4-wire methods at the same experimental conditions $\left(\mathrm{P}=1.5 \mathrm{GPa}, \mathrm{T} 900<\mathrm{T}<1340^{\circ} \mathrm{C}\right)$ than successful experiments, i.e. experiments providing sample conductivity measurements (Fig. SI 2). The results are compared with those of runs M496 and M480 (solid and liquid end-members respectively). At $\mathrm{T}>1350$, the resistance of the basalt melt becomes comparable with that of the short circuit obtained by the 2-wire set up, is 1 order of magnitude higher than the resistance obtained using the 4-wire method. From these observations, we conclude that the 4-wire technique is necessary.

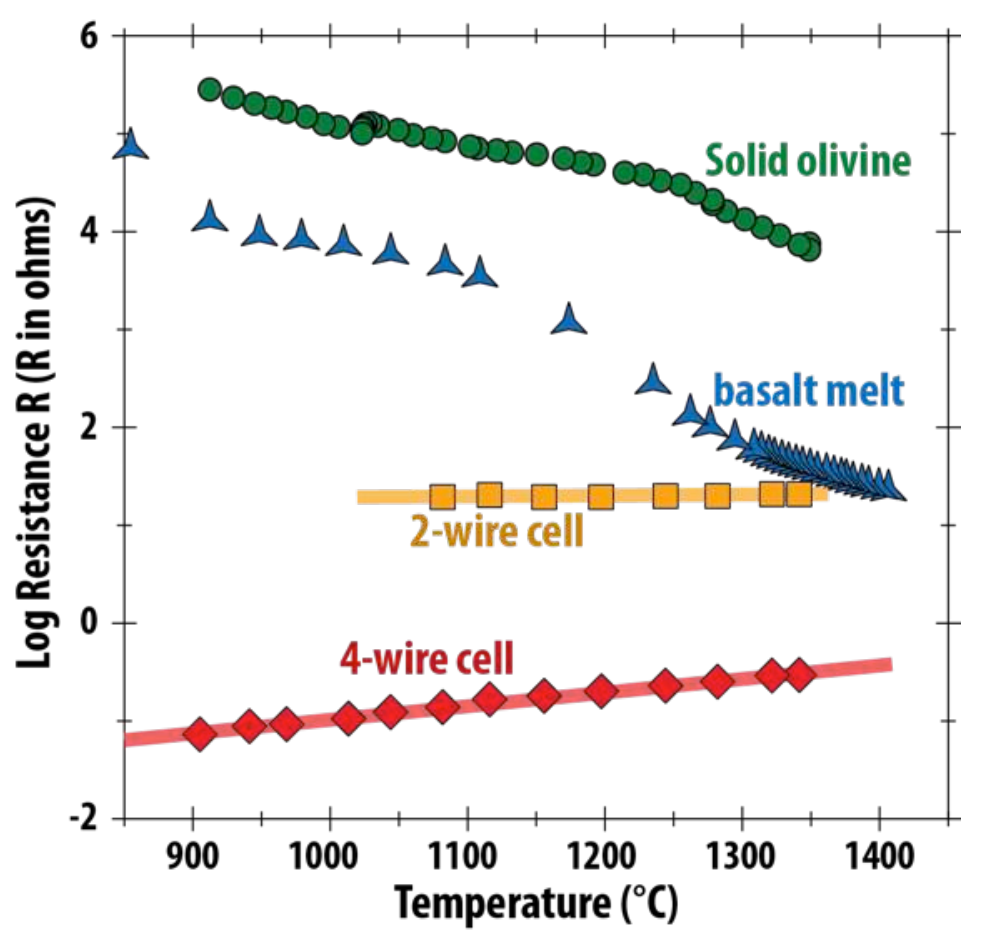

Fig. SI 2: Temperature vs. electrical resistance (log scale) of the short cut electrical cell using a 2- or 4-wire set up. The minimum resistance measurable with each setup is plotted alongside the resistance of the melt-free olivine aggregate (M496) and the one of the basaltic melt (M480). 


\section{EC variation over time (at $\mathbf{T}=$ constant)}

The reproducibility of the electrical conductivity measurements depends on several factors, the main ones being listed hereafter:

- The stability of the temperature

- The persistence of the sample dimensions

- The small deformation of the assembly, depending on the pressure steadiness

- The absence of melt migration

- The limitation of any chemical reaction of the sample with its surrounding materials

In order to (i) examine the stability of the measured conductivity, and (ii) explore a longer duration to track the melt distribution, one experiment (M523) with the first melt fraction below the interconnectivity threshold (0.25-0.50\%) was performed over 27 hours. The electrical conductivity decreases by 0.12 log unit over the first 10 hours (Fig. SI 3). The variation over 27 hours is within to 0.2 log unit. The electrical conductivity is mostly affected by small variations of the temperature $\left(1319^{\circ} \mathrm{C}+/-6\right)$ over short periods (tens of seconds) but also by the decrease of the temperature over hours: the average temperature difference between the first and the last hour is about $6^{\circ} \mathrm{C}$. Such a difference may result in the slow oxidation of the thermocouples, which discredits very long experiment using that setup. However, the very good reproducibility of the measurements over heating-cooling paths demonstrates the quality of the data presented in this study and the maximal duration of $\sim 6$ hours limits strong variation of the factors listed above.

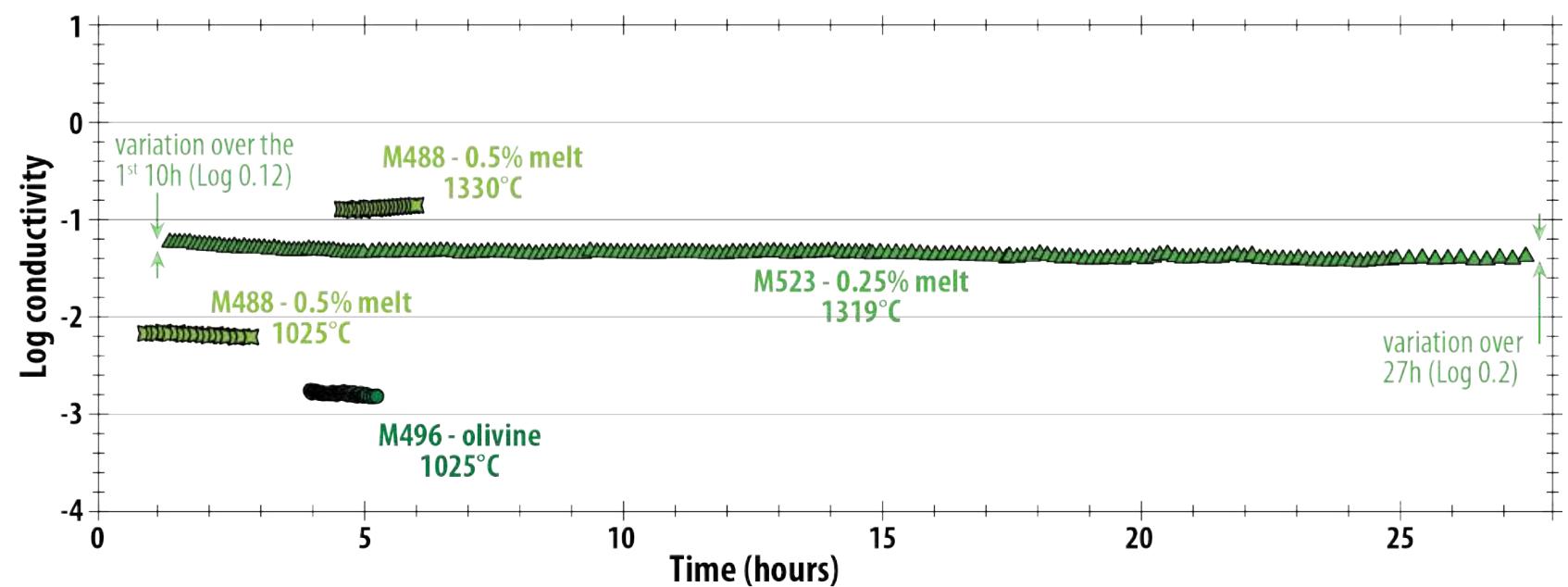

64 Fig. SI 3: Time vs. electrical conductivity (log scale) of M523 containing $0.25 \%$ of added basalt. The data is plotted the two pairs of vertical arrows during the first 10 hours and during the all experiment $\left(t=1319^{\circ} \mathrm{C}+/-6\right)$. 


\section{Extension of textural features}

\subsection{SEM and chemical mapping illustrations}

Fig. SI 4 shows supplementary SEM pictures illustrating the experiments not presented in the main text. The sample composed of basaltic melt only preserved its cylindrical shape and glassy texture, though little amount of melt infiltrated the MgO surrounding sleeve, (Fig. SI 4A). The electrode locally enriched in iron, but the glass still has a homogeneous composition experiments (Fig. SI 4C to L). Alongside the 2\% added basalt experiment, the experiment involving $10 \%$ of basalt also produced a peculiar melt pocket preferred orientation. As explained in the main text, the orientation parallel to the electrodes should not enhance the bulk conductivity; on the contrary, such an orientation refers to the parallel model tilted by

$7990^{\circ}$, providing depleted melt regions and thus, lowering the bulk conductivity normal to the concentrated-melt planes. 

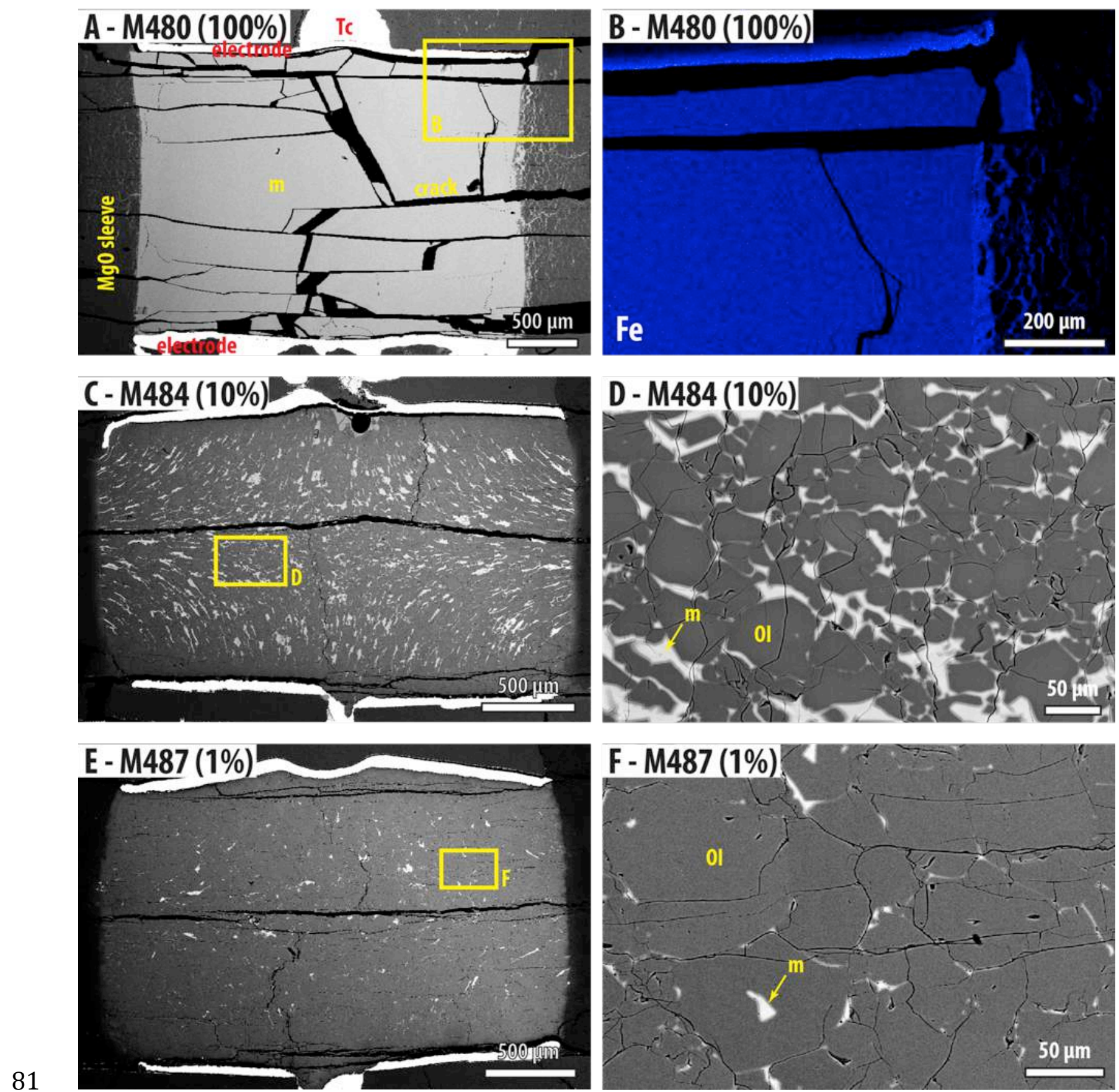

Fig. SI 4 (to be continued) 

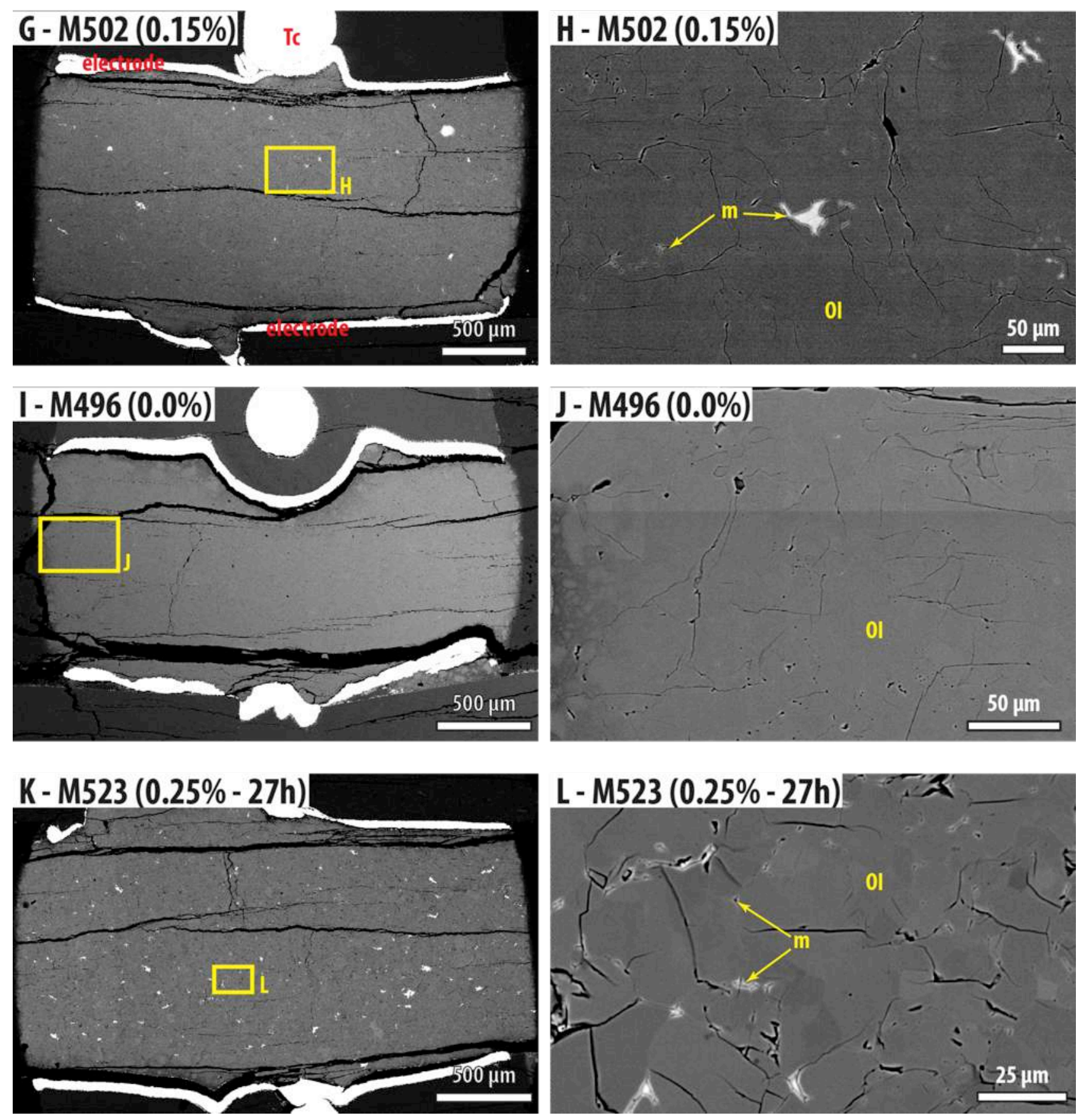

Fig. SI 4: SEM pictures of experiments and chemical mapping of iron in the basaltic glass (B). Tc, ol and $\mathrm{m}$ are thermocouple, olivine and melt respectively.

\subsection{Electron Backscatter Diffraction (EBSD)}

The EBSD patterns of sample M502 (0.15\%), M488 (0.5\%) and M484 (10\% of added basalt) were acquired on a ZEISS SEM, Leo Gemini 1530 with a Schottky field emission gun employing an accelerating voltage of $20 \mathrm{keV}$ and a beam current of about $2.0-2.5 \mathrm{nA}$ using a $60 \mathrm{~mm}$ aperture and the high current option. The specimens were placed at 14 to $17 \mathrm{~mm}$ working distance and we used a step size of $2.6 \mu \mathrm{m}$ for mapping. The microscope is equipped with a NordlysS camera, Oxford, with a CCD resolution of $1344^{*} 1024 * 12$ bit. Acquisition was set to 0.152 seconds per pattern and good pattern quality was obtained, while having a carbon 
coating of 3-6 $\mathrm{nm}$ thickness. Patterns were captured with $4 * 4$ binning on the camera, with 8 counts per window averaging, no background removal, minimum camera gain, and no image processing. Automated indexing routine and analyses was obtained using the software package CHANNEL 5 by HKL Technology. Automated SEM-EBSD measurements critically relay on the accuracy of the indexing procedure (Prior et al., 1999). We indexed olivine with the lattice parameters $\mathrm{a}=4.756 ; \mathrm{b}=10.207 ; \mathrm{c}=5.98$ and $\alpha, \beta, \gamma=90^{\circ}$. The reference file used the 6 strongest reflections of olivine, and no reference for the melt phase. $60-70 \%$ of the points were indexed; which is very good considering melt, cracks and pores are not indexed using conventional EBSD indexing routines. The reflections were calculated from the scattering factors of the atoms using the kinematical diffraction theory, even though it is not strictly fulfilled in this specific diffraction geometry, nevertheless the intensities of the reflections are approximately correct. In more than 51\% of the data points a good solution was found, the remaining map point were not indexed, partially this is a result of melt and cracks in the sample. The criteria for rejection a solution and thus not indexing were (1) if less than 5 reflection bands could be identified, were three non-coaxial bands are considered sufficient to yield a unique solution; (2) if the mean angular deviation of the calculated reflection bands in Hough space was larger than $1.5^{\circ}$. The main source of problems arising from the indexing algorithm is lower indexing success in pseudo symmetric related crystals across twin boundaries, usually lower indexing rates in on or the other twin-part, and indexing problems related to overlapping diffraction patterns from two crystals at grain boundaries, resulting in low confidence and thus no solution. To obtain maps with 100\% indexed data points we would have to assign grain boundary data points to orientations that are identical to the orientations of the majority of its eight neighbors and thus one or the other grain. However, due to the presence of a melt phase on some interfaces this is not a reliable method in the absence of a possibility to "index" the melt phase.

Further analyses were done using the MTex software package written by Ralf Hielscher and Florian Bachmann (e.g. Hielscher \& Schaeben, 2008; Bachmann et al., 2010, 2011). We corrected for the pseudo symmetry relation of $60^{\circ}$ rotation about the [100] axis in olivine and dilated the grains that had more than 5 connected pixels index that were distributed over several rows. The raw data and the results are displayed in figure SI 5 using the inverse pole figure color scheme of the TSL software. Crystal size distributions were calculated using both software package CHANNEL 5 by HKL Technology and the OIM TSL. The results are very similar and only the Channelf 5 results are displayed. 
Fig. SI 5 (next page): EBSD measurement results from samples M502 (column A), M488 (column B), M484 (column C). In the first row the orientation maps are displayed with respect to the compression direction (see legends), second row shows the number-weighted grain size distribution as $\ln$ (grain size), and the third row highlights the lattice preferred orientation (LPO) characteristics in pole figures, e.g. stereological projections of the three main crystallographic axis of olivine in the sample reference frame, where north-south is the compression direction, eastwest is the lineation in the foliation plane. We used a half-width of 10 in the orientation distribution function (ODF) estimation and the pole figures are projected in equal area, lower hemispheres. The contouring is fixed to a maximum of multiples of uniform distribution (MUD) of 4, to compare the LPO amongst the samples. 

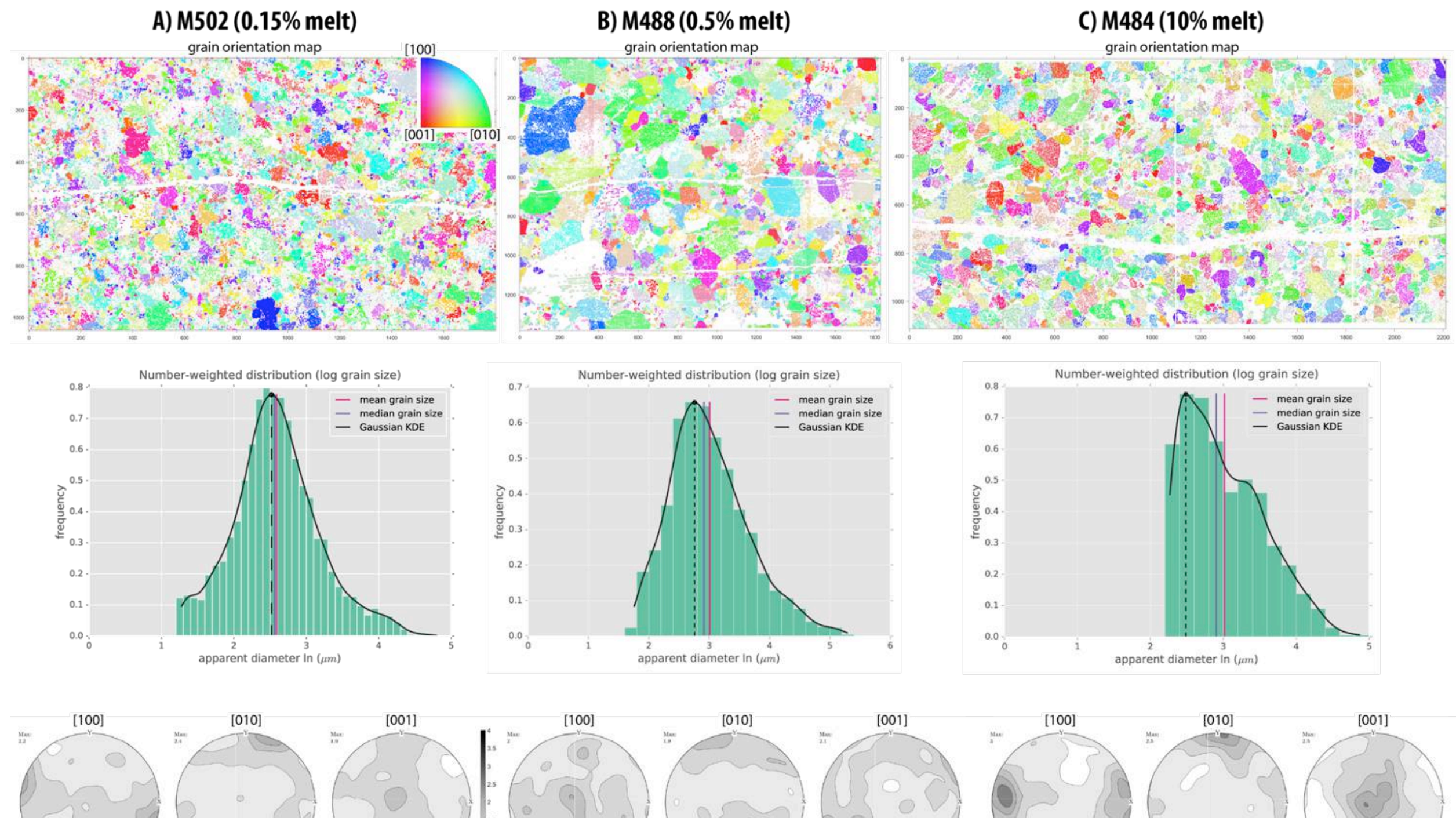


\section{Chemical composition of olivine and the glass}

140 Major elements

141 The variation of the chemical composition is more important for the melt than for olivine (Fig.

$142 \mathrm{SI}$ 6; Table 1). The $\mathrm{CaO}$ concentration decreases with the $\mathrm{SiO}_{2}$, and tends to increase with the 143 melt fraction. However, there is no clear evidence for a relationship between the melt fraction 144 and the $\mathrm{CaO}$ (nor other element) in the melt. Such a trend supports the idea of limited melting 145 of olivine since the lowest melt fractions would diverge the most from the starting basalt by 146 dilution of olivine elements.

148

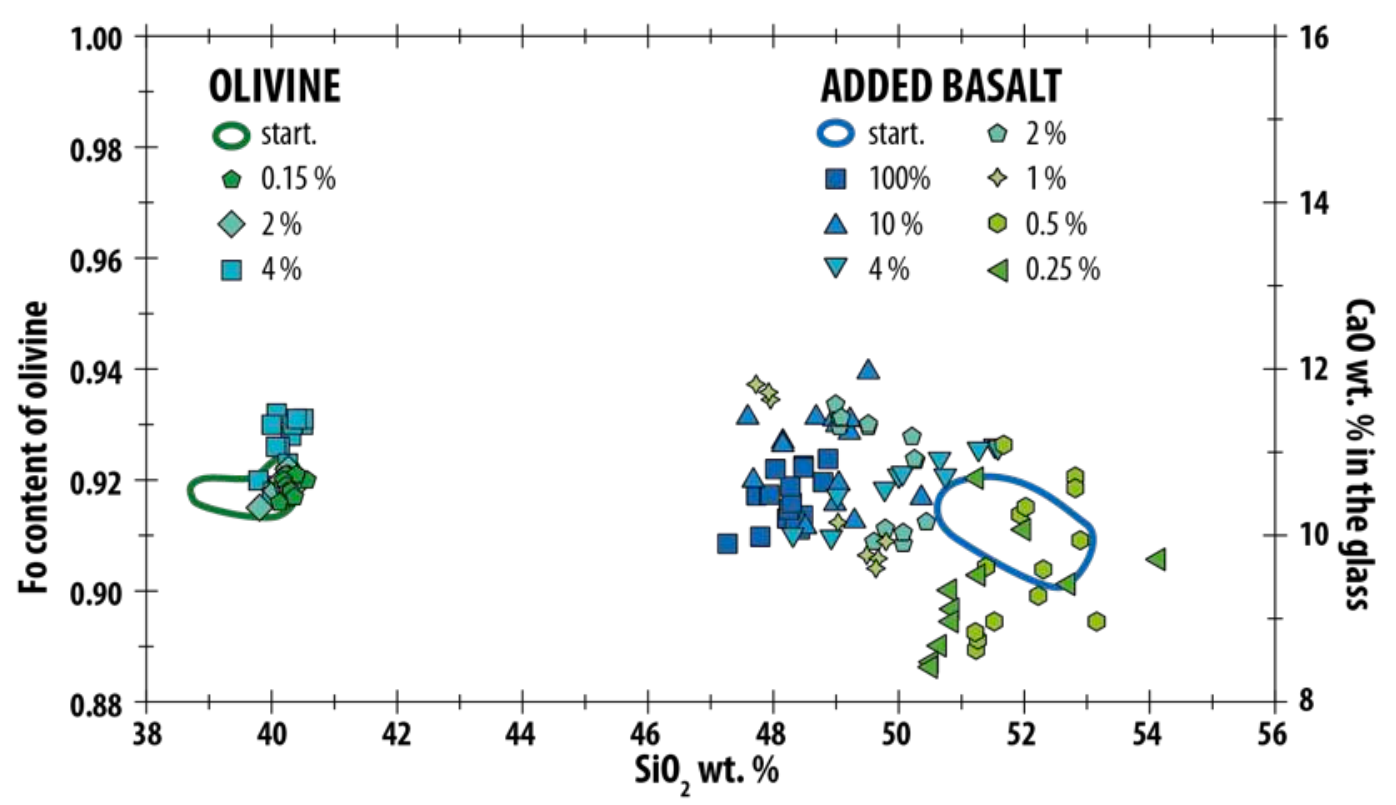

Fig. SI 6: Fo content (molar $\mathrm{Mg}$ - Fe ratio) of olivine and CaO concentration in the glass of various experiments.

\section{Extension on Secondary Ions Mass Spectrometer measurements}

The water content was measured using the Cameca IMS 1280HR of the SwissSIMS laboratory of the University of Lausanne (Switzerland). To minimize the water background in the machine, samples were mounted in indium, altogether with a reference material.

A $10 \mathrm{kV} \mathrm{Cs}^{+}$primary beam was used with a $\sim 1.5 \mathrm{nA}$ current. This resulted in a typical spot size of $\sim 10 \mu \mathrm{m}$ by few microns deep. The electron flood gun was used to compensate surface charge. ${ }^{16} \mathrm{OH}$ and ${ }^{16} \mathrm{O}$ secondary ions were accelerated by $10 \mathrm{kV}$ and analysed at a mass resolution of 5000 on a faraday cup sets with $10^{11} \Omega$ resistor and an electron multiplier, in multi-collection mode (slit 2 of multicollection and entrance slits closed at $61 \mu \mathrm{m}$ ). This resolution allows to resolve ${ }^{17} \mathrm{O}$ from ${ }^{16} \mathrm{OH}$. The detectors were calibrated in the beginning of the session. Before each measurement, the surface was cleaned using a $25 \mu$ rastered pre- 
163 sputtering beam, during 240 seconds. Each analysis took about 9 minutes, including the pre164 sputtering and automated centring of secondary ions in field and contrast apertures.

165 Mass calibration was performed at the beginning using basaltic glassy reference material with 166 a composition similar to the one used for EC experiments, and with different water 167 concentration (All107-D20, NS-1 and ALV519-4-1; Helo et al., 2011). A synthetic forsterite 168 containing less than $100 \mathrm{ppm}$ of water was used to monitor the instrument background for 169 water. Those 3 glassy reference materials have major element compositions similar to the 170 glasses from this study. The reference materials are all included in an indium mount, distinct 171 from the indium mount containing the unknowns. Reproducibility of the reference material 172 varies from 1 to 4 relative \% (2SD).

173 To be able to compare the unknown data with the reference material, a BHVO glass reference 174 material (USGS Standard) has been included with the reference material and the unknown. 175 BHVO, although not characterized for water, is also a basaltic glass and in quantity large 176 enough to be included in both mount. Reproducibility on repeated 4 measurements on BHVO 177 is $\sim 2 \%$ (2SD). The ${ }^{16} \mathrm{OH} /{ }^{16} \mathrm{O}$ ratio of BHVO has been compared between mounts.

178 A block of 4 analyses of BHVO was measured every 7 to 12 analyses to monitor the 179 instrument stability. A linear drift has been observed and corrected for. 


\section{Determination of the melt fraction}

182 Post-mortem glass fractions were measured from SEM pictures with various magnifications 183 (Fig. SI 7). A black and white threshold was applied on the pictures and the respective 2-D 184 fractions of solid and glass were calculated using the software SPO2003 (Launeau, 2004). No 185 correction from 2-D to 3-D was used.

186 The averaged fraction of glass is very similar to the initial fraction of basalt, though it depends on the magnification of the pictures. At low magnification $(<150 \mathrm{x})$, the melt fraction is underestimated, probably due to the difficulty to detect the small glass features (tubes, pockets). At higher magnification ( $>150 \mathrm{x})$, the fraction of glass is sometimes higher than the initial fraction because of the presence of pockets that locally increase the glass fraction. Due to the difficulty to precisely assess the post mortem fraction of glass, in particular at the lowest fractions, the initial proportion of added basalt is preferred in the following of the discussion.

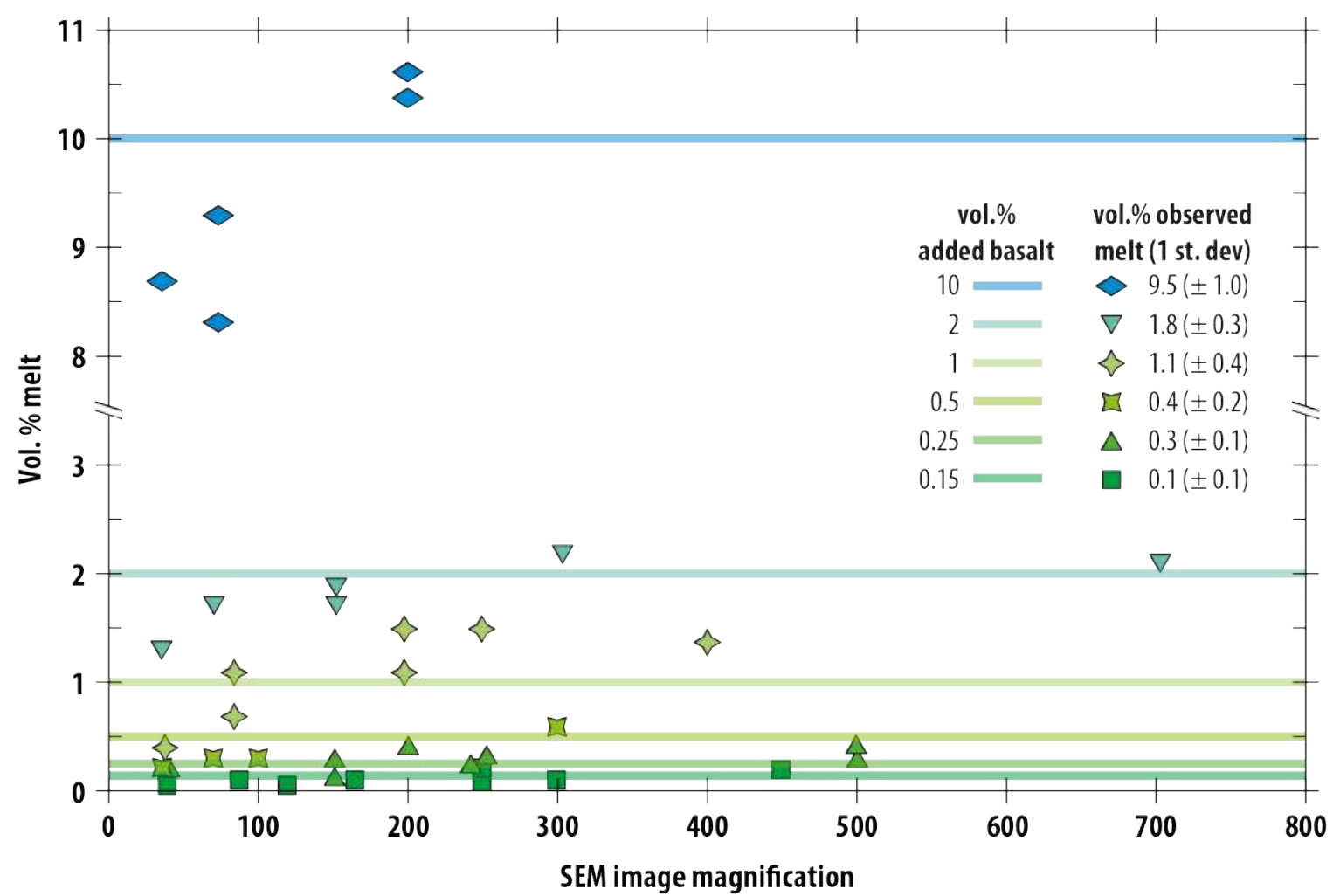

Fig. SI 7: proportion of melt (in volume \%) determined texturally after experiments on pictures with various magnification (symbols) and initial proportions of melt (lines) determined by mass of basalt added to olivine during sample preparation (described in section 2.1 of the main text).

\section{Activation Energy and influence of the melt in the olivine-only aggregate}

201 The activation energy $E_{a}$ is plotted against the fraction of the added basalt (Fig. SI 8). The $E_{a}$ of samples containing basalt decreases with the fraction of the added basalt, whereas the $\mathrm{E}_{\mathrm{a}}$ of 
203 the olivine-only sample is significantly higher. These observations suggest that although the 204 melt looks disconnected in the low (0.15 and $0.25 \%)$ melt fraction sample, the bulk 205 conductivity is governed by the melt. Also, the high $\mathrm{E}_{\mathrm{a}}$ of the olivine with no added melt 206 compared to the ones of melt-bearing aggregate supports the absence or the presence in low $207(<<0.15 \%)$ proportions of melt in the run with no added melt (M496).

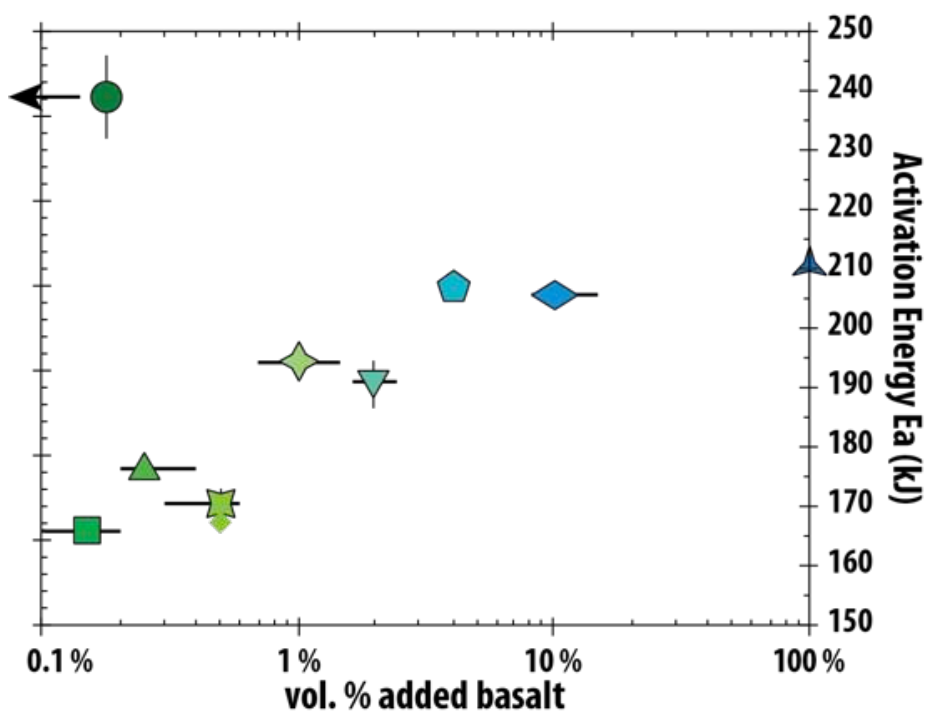

209 Fig. SI 8: fraction of added basalt vs. Activation Energy. The error on the melt fraction determined texturally is 210 represented by black bars. 


\section{8. Fit of the global model of melt-bearing olivine aggregate}

214 The model of melt-bearing olivine aggregate is plotted against the reciprocal temperature for 215 melt fraction corresponding to experiments according to Equation 3 and using the fitting 216 parameters $a$ to $d$ from $100 \%$ to 0.5 vol.\% of added melt (lines on Fig. SI 9) and using the 217 fitting parameters $a^{\prime}$ to $d^{\prime}$ from 0.5 to 0.15 vol.\% of added melt (dotted lines on Fig. SI 9). It 218 reproduces the experimental data very closely except for the $10 \%$ melt fraction experiment 219 that lies slightly below the model (Fig. SI 9). Such a difference could result in the anisotropic 220 melt distribution perpendicular to the shortest electrical path between the electrodes (Fig. SI 2214 C). When applying this model, one must pay attention to the temperature-melt fraction pair, 222 in particular at low melt fraction and high temperature.

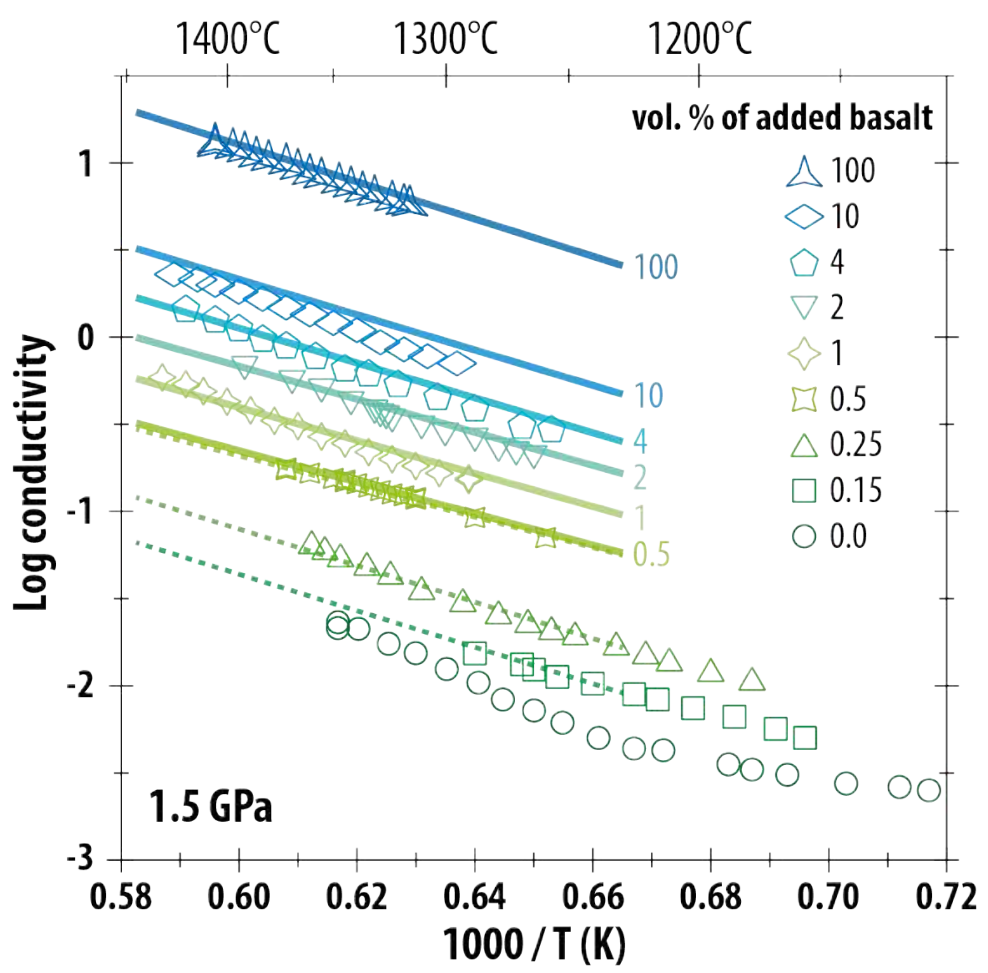

Fig. SI 9: Arrhenius plot of the general model of the partially-molten olivine aggregate (lines and dotted lines) compared with experimental data (symbols) obtained at $1.5 \mathrm{GPa}$.

\section{References}

Bachmann, F., Hielscher, R., and Schaeben, H. (2010) Texture Analysis with MTEX - Free and Open Source Software Toolbox. Solid State Phenomena, 160, 63-68.

Bachmann, F., Hielscher, R., and Schaeben, H. (2011) Grain detection from 2d and 3d EBSD data-Specification of the MTEX algorithm. Ultramicroscopy, 111, 1720-1733.

Helo, C., Longpré, M.A., Shimizu, N., Clague, D.A., Stix, J. (2011). Explosive eruptions at mid-ocean ridges driven by CO2-rich magmas. Nature Geoscience 4(4), 260-263. 
Launeau, P. (2004). Mise en évidence des écoulements magmatiques par analyse d'images 2-D des distributions 3-D d'orientations préférentielles de formes. Bull. Soc. Géol. Fr;, 175, 331-350. Prior, D.J., Boyle, A.P., Brenker, F., Cheadle, M.C., Day, A., Lopez, G., Peruzzo, L., Potts, G.J., Reddy, S., Spiess, R., Timms, N.E. (1999). The application of electron backscatter diffraction and orientation contrast imaging in the SEM to textural problems in rocks. American Mineralogist 84(11-12), 1741-1759. 